\title{
Rational Rock Physics for Improved Velocity Prediction and Reservoir Properties Estimation for Granite Wash (Tight Sands) in Anadarko Basin, Texas
}

\author{
Muhammad Z. A. Durrani, ${ }^{1}$ Keith Willson, ${ }^{2}$ Jingyi Chen, ${ }^{1}$ Bryan Tapp, ${ }^{1}$ and Jubran Akram ${ }^{3}$ \\ ${ }^{1}$ Department of Geosciences, University of Tulsa, 800 South Tucker Drive, Tulsa, OK 74104, USA \\ ${ }^{2}$ Newfield Exploration Company, 101 E 2nd Street, Tulsa, OK 74103, USA \\ ${ }^{3}$ Department of Geoscience, University of Calgary, 2500 University Dr. NW, Calgary, AB, Canada T2N 1N4
}

Correspondence should be addressed to Jingyi Chen; jingyi-chen@utulsa.edu

Received 22 January 2014; Revised 27 June 2014; Accepted 9 July 2014; Published 26 August 2014

Academic Editor: Rudolf A. Treumann

Copyright (c) 2014 Muhammad Z. A. Durrani et al. This is an open access article distributed under the Creative Commons Attribution License, which permits unrestricted use, distribution, and reproduction in any medium, provided the original work is properly cited.

\begin{abstract}
Due to the complex nature, deriving elastic properties from seismic data for the prolific Granite Wash reservoir (Pennsylvanian age) in the western Anadarko Basin Wheeler County (Texas) is quite a challenge. In this paper, we used rock physics tool to describe the diagenesis and accurate estimation of seismic velocities of $\mathrm{P}$ and $\mathrm{S}$ waves in Granite Wash reservoir. Hertz-Mindlin and Cementation (Dvorkin's) theories are applied to analyze the nature of the reservoir rocks (uncemented and cemented). In the implementation of rock physics diagnostics, three classical rock physics (empirical relations, Kuster-Toksöz, and Berryman) models are comparatively analyzed for velocity prediction taking into account the pore shape geometry. An empirical $\left(V_{\mathrm{p}}-V_{\mathrm{S}}\right)$ relationship is also generated calibrated with core data for shear wave velocity prediction. Finally, we discussed the advantages of each rock physics model in detail. In addition, cross-plots of unconventional attributes help us in the clear separation of anomalous zone and lithologic properties of sand and shale facies over conventional attributes.
\end{abstract}

\section{Introduction}

For the last sixty years, the Anadarko Basin has been a prolific setting for oil and natural gas explorations in North America largely focused on two natural gas plays: the Woodford shale and the Granite Wash. The exploration activity in the Granite Wash play has increased over the last decade. The Granite Wash play straddles the Oklahoma-Texas border and covers more than six counties (Hemphill, Roberts, Wheeler, Beckham, Roger Mills, and Washita) (Figure 1). The play is a series of stacked potential play zones, each of which should be treated differently and requires a more geophysically focused approach to achieve success. Due to the low porosity and permeability, cementation and the presence of microfractures make each interval a slightly different nut to crack [1].

Desmoinesian age (Granite Wash) deltaic sediments reflect a long diagenetic history, with extensive cementation by quartz and calcite. Postcementation secondary dissolution and leaching of calcite cement and framework grains (e.g., feldspar, rock fragments) produced/recovered current porosity in the facies [2]. The geological and depositional factors such as lithology, fluid, and porosity (LFP) directly affect the elastic properties of the rock and subsequently the seismic responses. Because of the complex nature of Granite wash, it has mystified geologists and petrophysicists as well as geophysicists alike, thus making geophysical experimental and numerical studies extremely challenging.

The solution to the problems requires rational rock physics to tackle complex mineralogy and poor understanding of diagenetic conditions to reexamine the current understanding of the reservoir properties of Granite Wash. Rock physics bridges the reservoir quantitative (e.g., Pand S-wave velocities, impedances, and elastic moduli) and reservoir qualitative (e.g., porosity, clay content, lithology, 


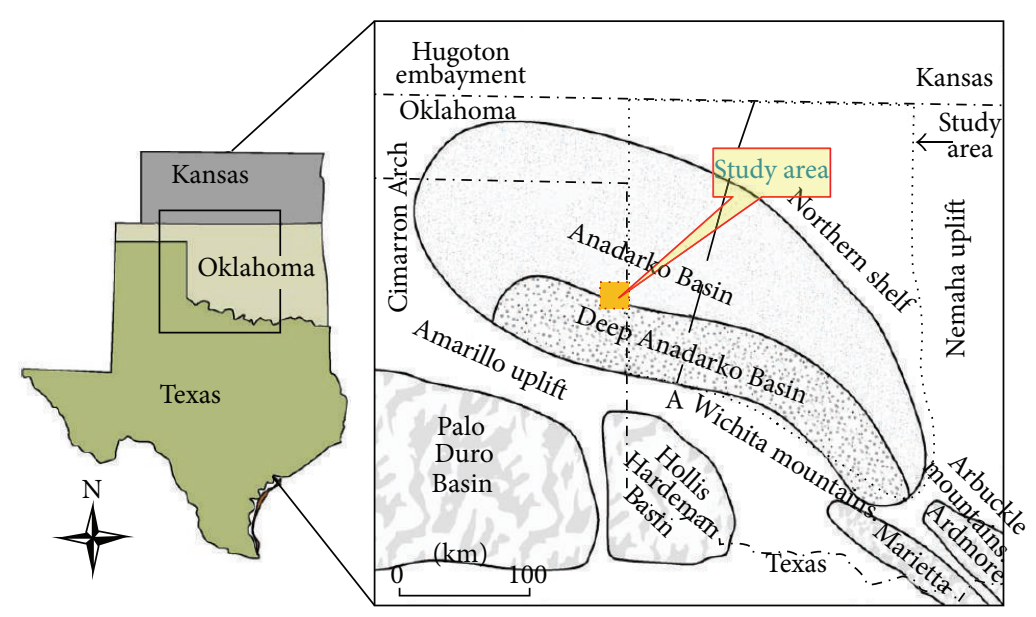

FIgURE 1: Location map of the study area Stiles Ranch field, Wheeler County, Anadarko Basin, Texas (USA).

and saturation) properties. In the past decade, rock physics for tight gas reservoirs has been relatively neglected due to their complex depositional and diagenetic histories [3]. Therefore, the ultimate goal here is to exploit a consistent methodology which can systematically integrate smallscale rock microstructure using the rock physic diagnostic approach for Granite Wash reservoirs in order to describe the diagenesis of Granite Wash and accurately estimate seismic ( $\mathrm{P}$ - and S-wave) velocities. To analyze the nature of the reservoir rocks (uncemented and cemented), we apply two rock physics models: (1) a rigorous contact model that is a combination of the Hertz-Mindlin [4] theory and modified Hashin-Shtrikman [5] elastic bounds (2) and Dvorkin's [6] cementation model based on cementation theory. Furthermore, we estimate and comparatively analyze seismic (P- and $\mathrm{S}$-wave) velocity predictions using effective medium theories and employ the optimal rock physics model to address the influence of pore shapes in granite wash sands from different aspects based on actual well data. Three standard rock physics [7-9] models are comparatively analyzed and discussed as to how pore shape influences the P-and S-wave velocities in the Granite Wash in the Anadarko Basin.

An empirical relation is established to predict S-wave velocity when there is only $\mathrm{P}$-wave data available for quartzitic sandstone that has not yet been defined and calibrated by Granite Wash core data. Finally, we applied Gassmann's equations in order to predict velocity changes resulting from different pore-fluid saturations and identified anomalous (hydrocarbons) zones by composite cross-plots of rock properties from well logs (Marmaton formation) data.

\section{Geologic Background}

The term Granite Wash generally refers to the sediments derived predominantly from the weathering of granitic rocks and closely resembles the original material [13]. The progression of Granite Wash plays in the Anadarko Basin started more than 300 million years ago as a result of sediment erosion of the Amarillo-Wichita uplift [10]. Large volumes of

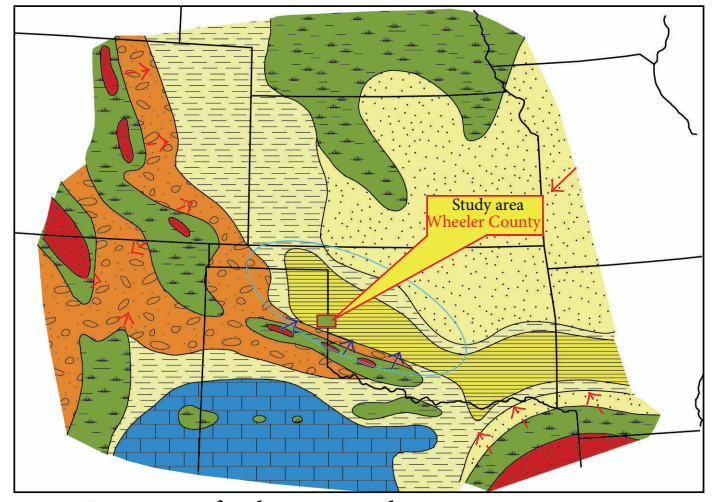

Direction of sediment supply

$\longleftarrow$ Major source

$<--$ Minor source

Land areas

$\square$ High or moderately high relief
Low relief

Marginal areas

High or moderately high relief

Low relief

Shallow marine

Principally carbonate deposition

Principally terrigenous clastic deposition

Deep marine

Principally terrigenous clastic deposition

Figure 2: Middle Pennsylvanian (Desmoinesian) paleogeography in Midcontinent area, from [10], modified.

clastic sediments were shed off the uplift and deposited to the north in the rapidly subsiding Anadarko Basin (Figure 2).

Varieties of depositional settings have been postulated for various reservoirs in the Granite Wash that include braidedstream, alluvial-fan, fan-delta, turbidite, and debris-flow environments [14]. The deposition in the Anadarko Basin occurred in a series of alluvial fans and fan deltas that formed 


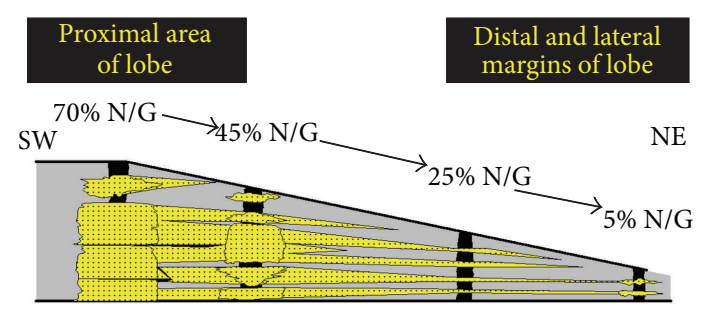

FIGURE 3: Depositional facies distribution of Granite Wash from proximal to distal settings from [11]. Data is courtesy of Newfield Exploration Company.

rims around the structural highs that developed during the Pennsylvanian period [15]. In proximal submarine fan settings (Texas), the Washes are thick-bedded (amalgamated) sheet sands, poorly sorted and coarse-grained [11]. Granite Wash thickness varies from 1,500 to $3,500 \mathrm{ft}$ of interbedded conglomerate and amalgamated sheet sandstones deposited in deeper water setting as turbidite and/or debris-flow deposits. Distal submarine fan settings (Oklahoma) contain very thin-bedded sheet sands that have interbedded shales with decreased N/G ratio, well sorted, silt to fine-grained, minor clay, and abundant carbonate cements (Figure 3).

Rock composition is mainly influenced by deposition and unroofing of Siluro-Devonian and Mississippian carbonates and discontinuity of beds, which are often very thin, laterally discontinuous, and diagenetically altered (cemented). From proximal to distal settings, the rock pore shape geometry changes due to several geological processes including initial deposition of fine to very fine grained sediments and the presence of various types of dispersed shales and clays in the pores [16]. Figure 4 shows highly variable grain size and mineralogy with reduced porosity as a result of variable formation lithology, substantial cementation, and cuspate to triangular/rectangular geometries tied to the geological character of the sediment source areas in the immediately adjacent Amarillo-Wichita Mountains [11].

Figure 5(a) provides the generalized stratigraphic column of the Anadarko Basin. Thick deposits of Granite Wash are made up of varying sizes of tight sands containing more than a dozen underground formations stacked on top of the others, each holding vast quantities of hydrocarbons [12]. The production has mainly come from the targeted Desmoinesian (middle Pennsylvanian) series reservoirs, with additional production from Atoka, Missourian, and Virgilian series units (Figure 5(b)). The target depths in the study area range from 12,000 to 16,500 ft. Examination of more than 100 cores was studied by Core Lab. Reference [11] in proximal and distal fan settings from the Pennsylvanian Granite Wash section reveals a complex diagenetic history which is a function of the depositional environment and the thermal history of the basin.

\section{Data Set}

The principal data sources for rock physics diagnostics are well logs and core measurements. Log data includes P- and
S-wave velocities, density, gamma ray, and resistivity. We incorporated the core study that has already been done by Newfield Exploration Company (Tulsa, OK, USA) which contains a series of laboratory experiments performed on the Granite Wash core samples yielding their petrophysical properties that are the key for calibrating and improving the rock physics modeling.

\section{Rock Physics Theory}

Generally, the velocities depend on the ratio rock moduli to density. The moduli and density effects generate velocity variations which depend on the rock properties such as porosity, fluid saturation, and texture. The seismic (P- and Swave) velocities of an isotropic rock material can be estimated using known rock moduli and density as follows:

$$
\begin{aligned}
& V_{\mathrm{P}}=\sqrt{\frac{K_{\mathrm{sat}}+(4 / 3) \mu_{\mathrm{sat}}}{\rho},} \\
& V_{\mathrm{S}}=\sqrt{\frac{\mu_{\mathrm{sat}}}{\rho_{\text {sat }}}},
\end{aligned}
$$

where $K$ is bulk modulus, $\mu$ is shear modulus, and $\rho$ is the bulk density.

Generally, P- and S-wave velocities are not considered the best fluid indicator due to the coupling effect between $\mathrm{P}$ - and S-waves through the shear modulus and bulk density [17]. Rock physics trends appear more discretely in the modulus-porosity plane than in the velocity-porosity plane. Bulk modulus shows sensitivity to pore fluid (water) and deformation produced by a seismic wave resulting in change of pore volume. Shear modulus usually does not produce a pore-volume change and consequently is not affected by different fluids. The work space for rock physics analysis is the rock physics plane that may be (a) velocity-porosity; (b) impedance-porosity; and/or (c) modulus-porosity plane. Primarily, we prefer elastic moduli-porosity planes to correlate fluid effects change in bulk modulus in comparison with velocity-porosity planes for diagnosing rock.

We apply Dvorkin's [6] rock physics diagnostics technique to log data from the Granite Wash (Marmaton section), calibrated with core data from a well in Stile Ranch field Wheeler County, Texas, USA (Figure 6). Technique is applied by using Hertz-Mindlin contact theory combined with theoretical elastic bounds (Hashin-Shtrikman [5] bounds) and cementation theory based mathematical model (see overview in $[6,18]$ ) to analyze the elastic signatures of porosity reduction related to depositional sorting and diagenesis (mechanical and chemical compaction). First, pressure dependent Hertz-Mindlin contact theory is used to estimate the dry moduli of the rock at critical porosity (0.40) end member. Then, we constructed moduli of the solid mineral for zero porosity. The moduli of the dry rock between high porosity (critical porosity) and zero porosity are estimated by Hashin-Shtrikman bounds, which provide theoretical approximations of effective elastic moduli of a mixture of grains and pores. Hashin-Shtrikman bounds 


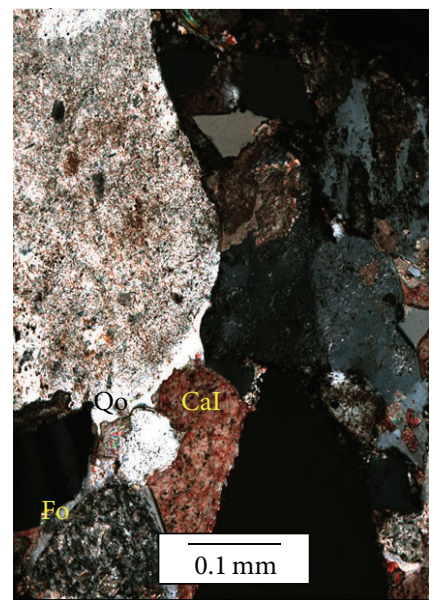

(a)

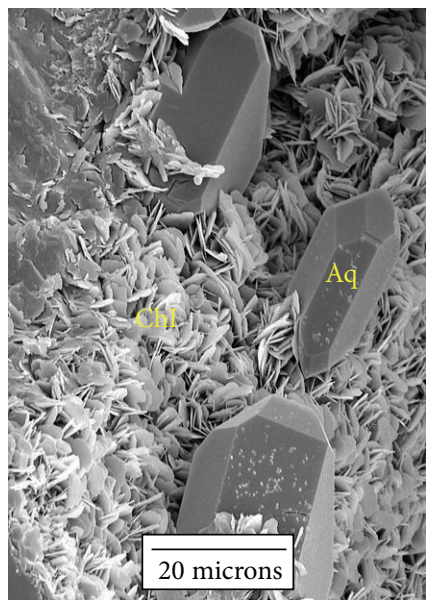

(b)

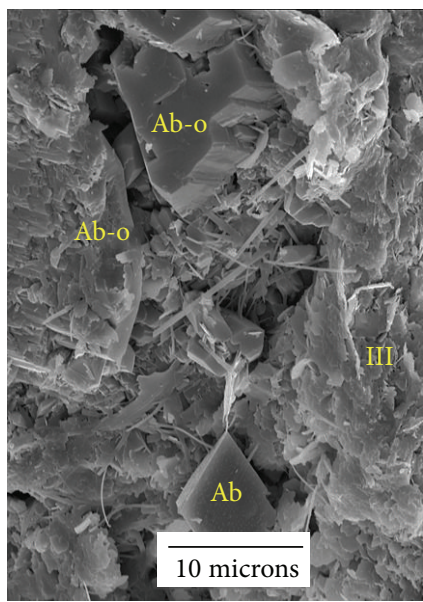

(c)

FIGURE 4: Petrography and mineralogy Granite Wash (Marmaton section) sandstones pore-filling constituents are (a) calcite fill pores and quartz overgrowths, feldspar overgrowths; (b) euhedral microquartz crystals; and (c) authigenic albite overgrowths and single crystals from [11]. Data is courtesy of Newfield Exploration Company.

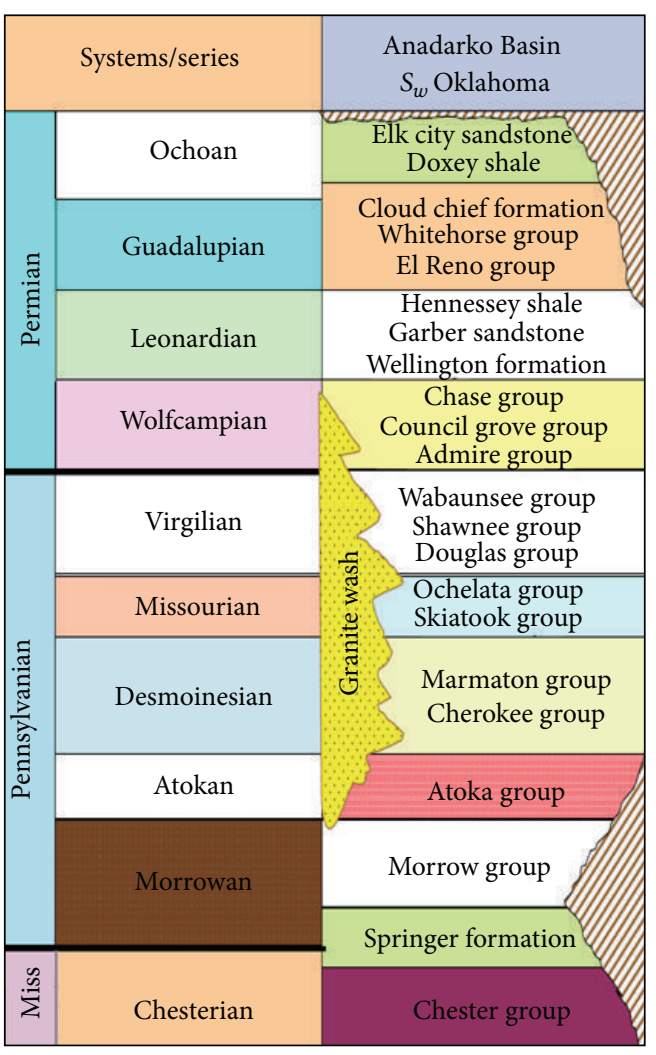

(a)

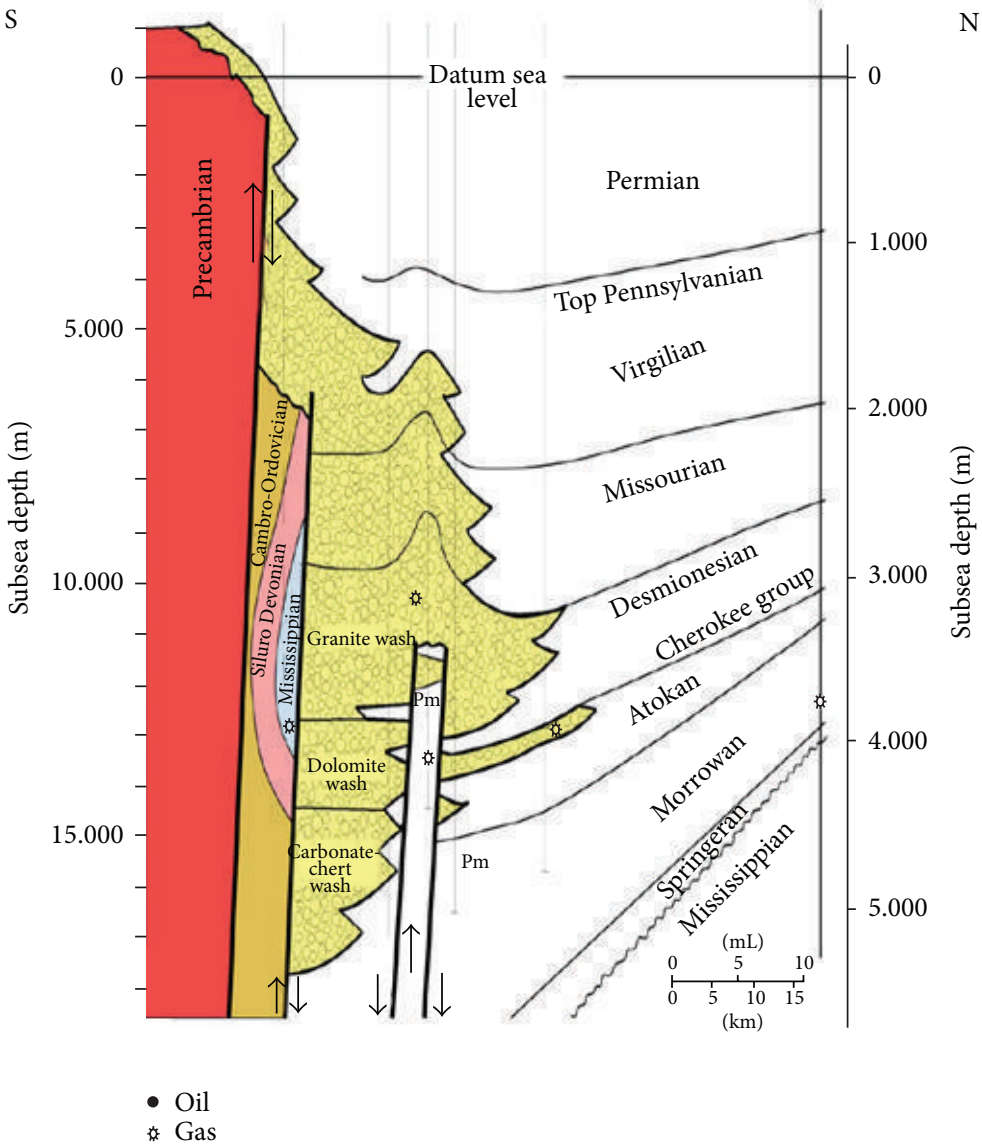

(b)

Figure 5: (a) Anadarko Basin stratigraphic column [12] and (b) stratigraphic dip cross-section-unroofing sequence [11]. 

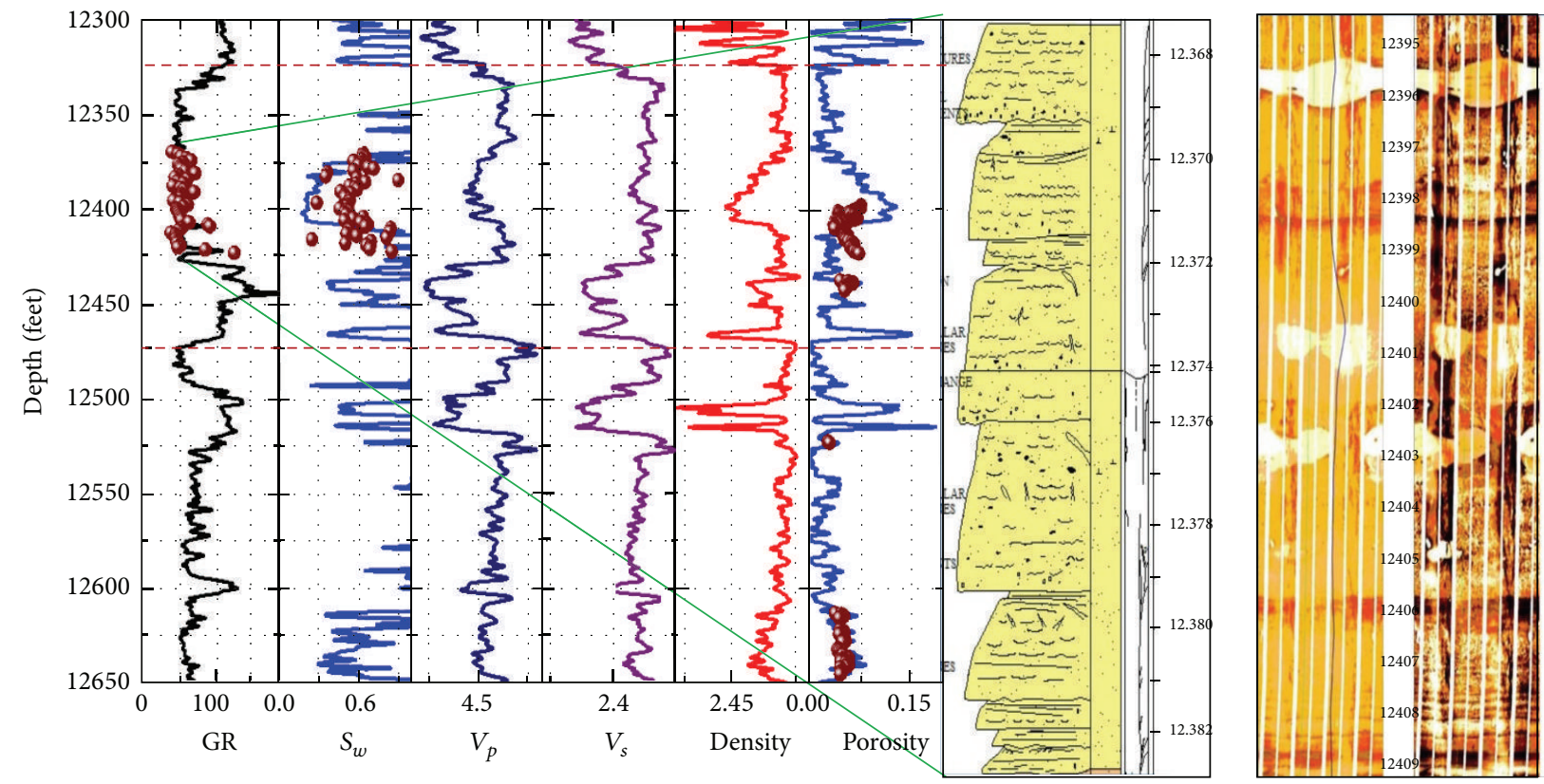

FIGURE 6: Well log curves from Stiles Ranch field, Wheeler County Anadarko Basin, Texas (USA). From left to right: GR (API), $S_{w}, V_{\mathrm{P}}(\mathrm{Km} / \mathrm{s})$, $V_{\mathrm{S}}(\mathrm{Km} / \mathrm{s})$, density $(\mathrm{g} / \mathrm{ccc})$, porosity, and FMI logs with superposed core [11] data (maroon). Data is courtesy of Newfield Exploration Company.

assume that each component and the rock are isotropic and elastic [18].

The behaviors of elastic properties due to cementation is captured by contact-cement model [6]. The cement model assumes that porosity decreases from the initial critical porosity value due to the uniform deposition of cement layers on the surface of the grains. This cement may be diagenetic quartz, calcite, or reactive clay (such as illite). The diagenetic cement dramatically increases the stiffness of the sand by reinforcing the grain contacts. The mathematical model is based on a rigorous contact-problem solution by Dvorkin et al. $[19,20]$. It is assumed that the microstructure used in the models quantitatively mimics the data. The rock diagnostic was conducted on the log scale and was confirmed with the core data (thin sections).

Furthermore, we employ effective medium [7, 9] models in order to estimate and comparatively analyze seismic velocity (or moduli) based on pore aspect ratio to characterize the appropriate pore-shape factor in the Granite Wash reservoirs. The generalized formulas of the Kuster-Toksoz [9] model are expressed by Berryman [7] as follows:

$$
\begin{aligned}
\left(K_{K T}-K_{m}\right) \frac{\left(K_{m}+(4 / 3) \mu_{m}\right)}{\left(K_{K T}+(4 / 3) \mu_{m}\right)} & =\sum_{i=1}^{N} x_{i}\left(K_{i}-K_{m}\right) P^{m i}, \\
\left(\mu_{K T}-\mu_{m}\right) \frac{\left(\mu_{m}+\zeta_{m}\right)}{\left(\mu_{K T}+\zeta_{m}\right)} & =\sum_{i=1}^{N} x_{i}\left(\mu_{i}-\mu_{m}\right) Q^{m i},
\end{aligned}
$$

where the summation is over the different inclusions with volume concentration $x_{i}$ and

$$
\zeta=\frac{\mu}{6} \frac{(9 K+8 \mu)}{(K+2 \mu)} .
$$

The coefficients $P^{m i}$ and $Q^{m i}$ describe the effect of an inclusion of material " $i$ " in a background medium $m$; inclusion; coefficients $P$ and $Q$ describe the elastic properties of the pore phase (Table 1). Two types of calculation algorithms for the coefficients $P$ and $Q$ are followed: (1) The Kuster-Toksoz model (spheroidal inclusions) with arbitrary pore aspect ratio is named 2DKT model, and (2) Berryman's [7] 3D special pores (penny-shaped crack) are called 3DKT model.

To estimate the effect of the pore fluids on the elastic properties, Gassmann's [21] fluid substitution approach is used to model different scenarios. Gassmann's equations relate the bulk modulus of a rock to its pore, frame, and fluid properties. The bulk modulus of a saturated rock is given by the Gassmann theory:

$$
K_{\text {sat }}=K_{d}+\frac{\left(1-K_{d} / K_{m}\right)^{2}}{\left(\phi / K_{f}\right)+\left((1-\phi) / K_{m}\right)-\left(K_{d} / K_{m}^{2}\right)},
$$

where $K_{\text {sat }}$ the bulk modulus of a rock is saturated with a fluid of bulk modulus $K_{f} ; K_{d}$ is the frame bulk modulus; $K_{m}$ is the matrix (grain) bulk modulus; and $\phi$ is porosity. Consider

$$
\mu_{\text {sat }}=\mu_{d} \text {. }
$$

The bulk density $\left(\rho_{\text {sat }}\right)$ is obtained from mass balance equation

$$
\rho_{\text {sat }}=\rho_{m}(1-\phi)+\phi \rho_{f},
$$

where $\phi, \rho_{\text {sat }}, \rho_{m}$, and $\rho_{f}$ are, respectively, the porosity, density of saturated rocks, the matrix, and pore fluids. The density of the solid (mineral) phase is $\rho_{m}=(1-C) \rho_{q}+C \rho_{c}$.

In this study, we take assumptions that reservoir sandstone mineral grains are mainly (a) cemented; (b) spherical 
TABle 1: Coefficients of $P$ and $Q$ for some specific shapes. The subscripts " $m$ " and " $i$ " refer to the background and inclusion materials [7].

\begin{tabular}{lcc}
\hline Inclusion shape & \multicolumn{1}{c}{$P^{m i}$} & $Q^{m i}$ \\
\hline Spheres & $\frac{K_{m}+(4 / 3) \mu_{m}}{K_{i}+(4 / 3) \mu_{m}}$ & $\frac{\mu_{m}+\zeta_{m}}{\mu_{i}+\zeta_{m}}$ \\
Needles & $\frac{K_{m}+\mu_{m}+(1 / 3) \mu_{i}}{K_{i}+\mu_{m}+(1 / 3) \mu_{i}}$ & $\frac{1}{5}\left(\frac{4 \mu_{m}}{\mu_{m}+\mu_{i}}+2 \frac{\mu_{m}+\gamma_{m}}{\mu_{i}+\gamma_{m}}+\frac{K_{i}+(4 / 3) \mu_{m}}{K_{i}+\mu_{m}+(1 / 3) \mu_{i}}\right)$ \\
Disks & $\frac{K_{m}+(4 / 3) \mu_{i}}{K_{i}+(4 / 3) \mu_{i}}$ & $\frac{\mu_{m}+\zeta_{i}}{\mu_{i}+\zeta_{i}}$ \\
Penny cracks & $\frac{K_{m}+(4 / 3) \mu_{i}}{K_{i}+(4 / 3) \mu_{i}+\pi \alpha \beta_{m}}$ & $\frac{1}{5}\left(1+\frac{8 \mu_{m}}{4 \mu_{i}+\pi \alpha\left(\mu_{m}+2 \beta_{m}\right)}+2 \frac{K_{i}+(2 / 3)\left(\mu_{i}+\mu_{m}\right)}{K_{i}+(4 / 3) \mu_{i}+\pi \alpha \beta_{m}}\right)$ \\
\hline
\end{tabular}

TABLE 2: The core values of moduli and densities of minerals and fluids used in this study [11].

\begin{tabular}{lccc}
\hline Minerals and fluids & $\begin{array}{c}\text { Density } \\
(\mathrm{g} / \mathrm{cc})\end{array}$ & $\begin{array}{c}\text { Bulk modulus } \\
(\mathrm{GPa})\end{array}$ & $\begin{array}{c}\text { Shear modulus } \\
(\mathrm{Gpa})\end{array}$ \\
\hline Quartz & 2.65 & 55.80 & 38 \\
Clays & 2.58 & 20.9 & 6.85 \\
Dolomite & 2.87 & 80.10 & 45.00 \\
calcite & 2.71 & 75.50 & 34.00 \\
Oil & 0.7 & 1.62 & - \\
Gas & 0.12 & 0.032 & - \\
\hline
\end{tabular}

shape; and (c) randomly packed. From the core study, the percentage volume of the rock matrix is dominantly clay (15\%) and quartz (40\%). The basic parameters used for fluids properties in velocity prediction were taken from core studies (Table 2). Analysis of log and core data from well A suggests that these assumptions are met for our reservoir.

\section{Data Analysis and Results}

5.1. Rock Physics Diagnostics Application to the Granite Wash. A common practice in rock physics analysis is to generate cross-plots of elastic properties to study diagenetic trends and property dependencies of sands and shales. The cross-plots exhibit interdependence among the various rock properties. We particularly focused on a thick Marmaton Wash section (12325-12435ft) of well number A containing various log curves (Figure 6). Marmaton section is marked by extremely low and fairly constant (about 37.5) gamma-ray readings and high velocity (about $4.6 \mathrm{~km} / \mathrm{s}$ ) surrounded by shale packages.

In spite of the congruency between different log curves in Figure 6, various cross-plots of Marmaton sands do not produce unique trends (Figure 7). In Figure 7(a), low and high "GR" sediments do not show huge variations in bulk density, implying that both sand and shale are well compacted and cemented; Figure 7(b) shows the same as the case in GR-porosity plot; and Figure 7(c) shows that presence of clay with significantly lower impedance than the quartz it cements. Figures 7(d), 7(e), and 7(f), modulus/velocity versus porosity cross-plots, show $V$ shape overturned paths. The superimposed $V$-shaped paths actually represent clay content from clean sands to pure shale. The sands overlapped with the clean shales probably indicate the sand cluster including both clean and shaly sands [22]. From moduli-/velocityporosity cross-plots, we can assess the progress of diagenesis and compaction trends of sediments. For soft or uncemented and stiff sediments, the paths are fairly gentle, with not much of velocity contrast between sands and shales. For cemented sediments (case under examination), increasing depth quartz cementation provides a large contrast in velocity from shaly sands to the pure shales. This drop might be associated with the effect of proceeding from grain supported to clay-supported sediments under relatively high effective pressure $[23,24]$. Thus, a large part of the scatter observed in moduli/velocity versus porosity plots is due to presence of clay in the rocks.

We construct the Hashin and Shtrikman [5] bounds (upper and lower) to conceptually explain and model the data scatter of the Granite Wash from four different wells (Figure 8). The bounds provide an idea of the narrowest possible range of elastic moduli without a detailed description of the microstructure of Granite Wash rocks. For bounds, only volume fractions of the constituents, quartz is $40 \%$ by volume of solid fraction; calcite is $7 \%$ by volume of solid fraction; and their elastic moduli obtained from core data are used without specifying the geometric details of their arrangements. The upper and lower bounds are determined by exchanging the materials, one that fills the pores and another constructing the shell. The upper bound is realized when stiffer material forms the shell; the lower bound is realized when the stiffer material is physically present in the core of the shell [18]. The separation between upper and lower bounds shows how elastically different the constituents are. The elastic contrast between pure sand and the critical concentration mixture is relatively strong because of the variable elastic contrast between quartz and clay grains. This implies that the effect of quartz and clay minerals may be critical for seismic interpretation of Granite Wash.

Moduli-porosity data point superimposed with core data fall between the upper and lower bounds, which indicates that Marmaton sands are consolidated sandstone with cementations. Superimposed core data from Marmaton section confirms the presence of quartz and calcite cement.

5.2. Confirming the Diagnostic. From Figure 4, we observe that microcrystalline quartz is found in close contact between grains, so this quartz cement has a stiffening effect on 


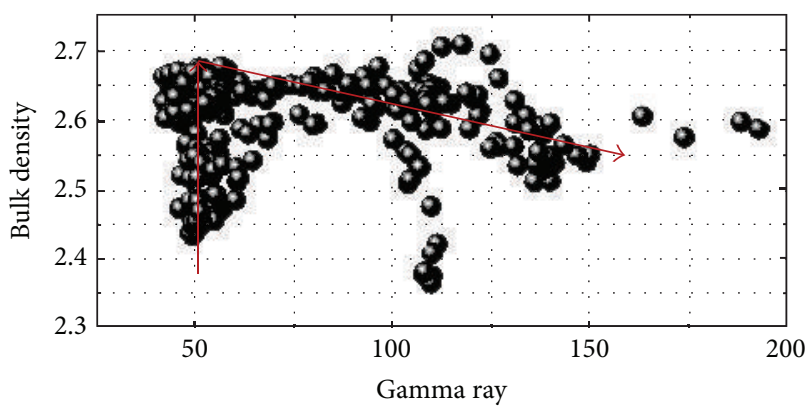

(a)

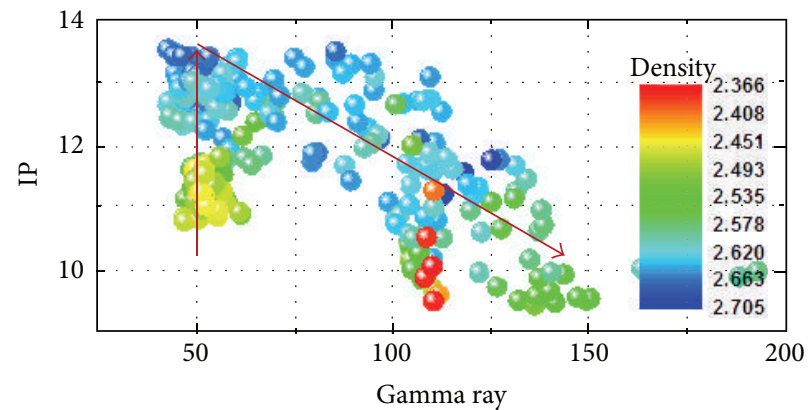

(c)

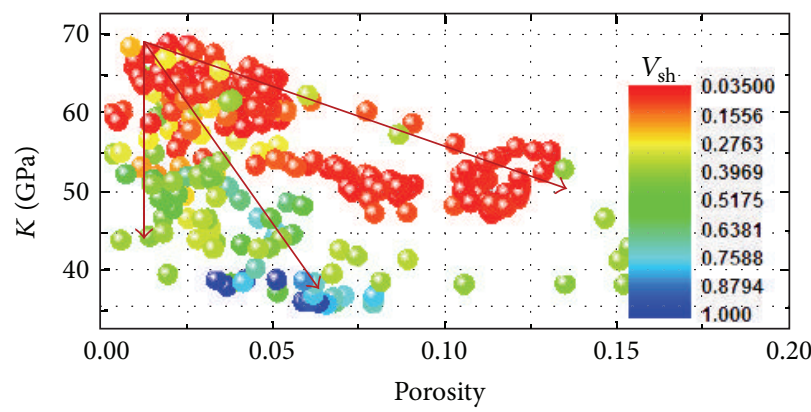

(e)

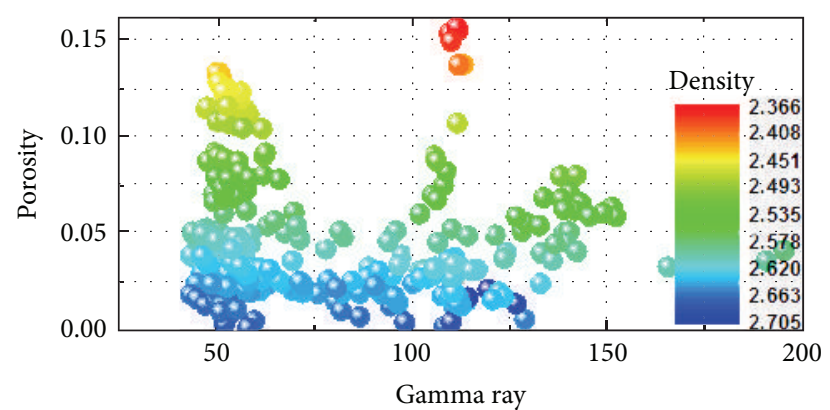

(b)

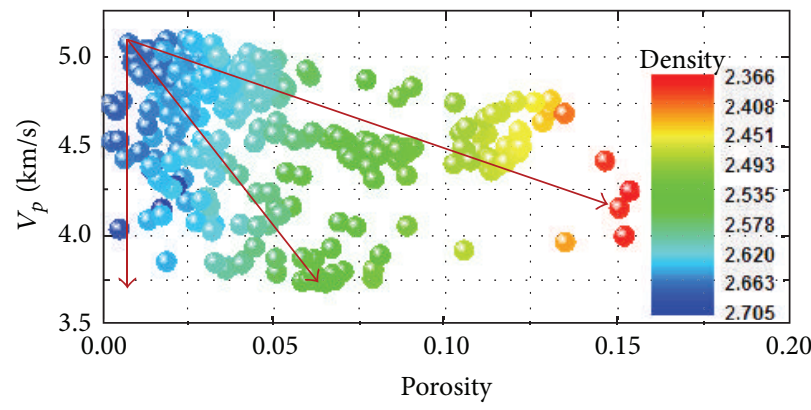

(d)

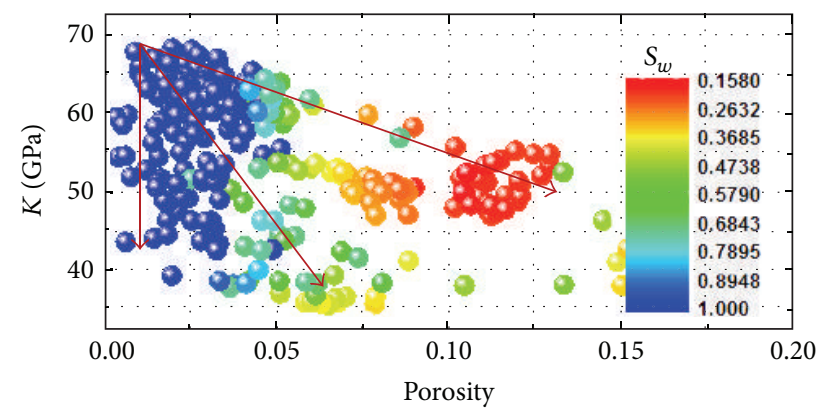

(f)

FIGURE 7: Cross-plots of Well log data Marmaton section from Figure 6: (a) bulk density versus GR; (b) total porosity versus GR color coded by density; (c) P-wave impedance versus GR color coded by density; (d) P-wave versus total porosity color coded by density; (e) bulk modulus versus total porosity color coded by shale volume $\left(V_{\mathrm{sh}}\right)$; and (f) bulk modulus versus total porosity color coded by water saturation $\left(S_{w}\right)$.

the elastic properties of the Granite Wash. Studies have supported the fact that dissolution and local precipitation of quartz, accompanied by compaction, cause long term deformation of the aggregate, resulting in permeability and porosity reduction [25]. Hence, quartz precipitation between the grains causes major porosity reduction.

For diagnostic purposes, we cross-plotted the elastic properties from well number A (Marmaton section) in velocity-porosity and moduli-porosity planes, superimposing theoretical rock physics models (Figure 9). The crossplots show that gradually increasing clay content with depth corresponds with decreasing elastic value. Based on laboratory data, log data, thin section analysis, and rock-physics models, the data is sorted into Dvorkin and Nur's [6] following three schemes: uncemented (or soft) Washes, Washes with small amounts of quartz cement at grain contacts (scheme 1), and Washes from the same formation but with clay cement (scheme 2). The upper two theoretical (schemes 1 and 2) curves correspond to the pure quartz cases while lower curve is for pure clay or uncemented rock. Scheme 1 represents all cement deposited precisely at grain contacts and the slope steep. Scheme 2 curve corresponds to the case where the contact cement region is formed at the intersection of cement shells that are uniformly deposited on grain surfaces; cement fills the space of the large pores and results in a flat slope. It is quite possible that the variation in microcracks may be the major reason why the slope of velocity-porosity and modulus-porosity planes differs in different schemes.

We noticed that the maximum data points fall on the rock physics scheme 2 line representing uniformly deposited cement on grain surface. The thin sections samples from well number A confirmed the rock diagnostic that with increasing depth and pressure, the decreasing porosity is a result of contact cement in the rock-physics cross-plots. It is quite 

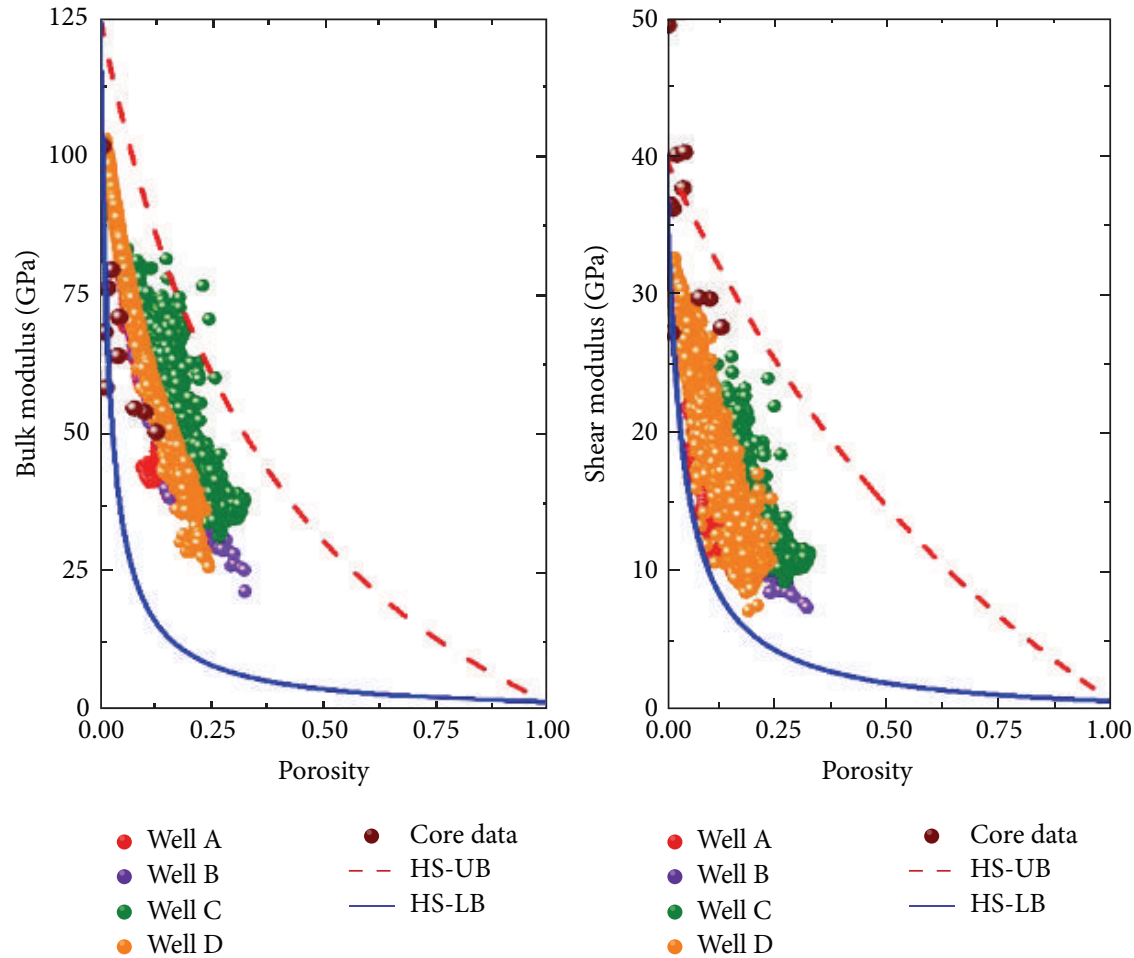

FIGURE 8: Moduli versus porosity for different wells and core [11] data with superposition of Hashin and Shtrikman [5] bounds.

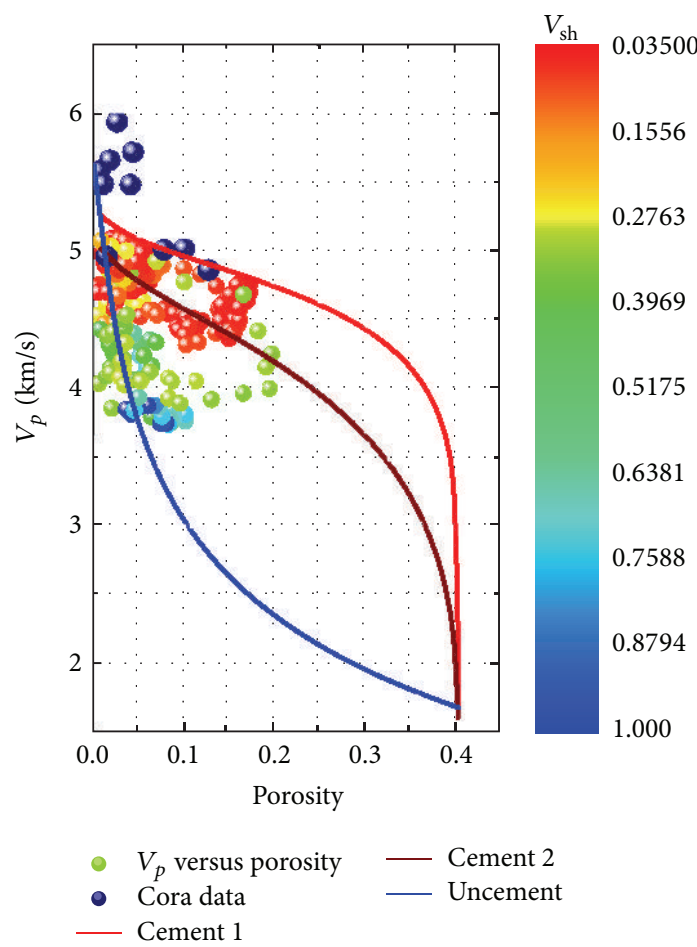

(a)

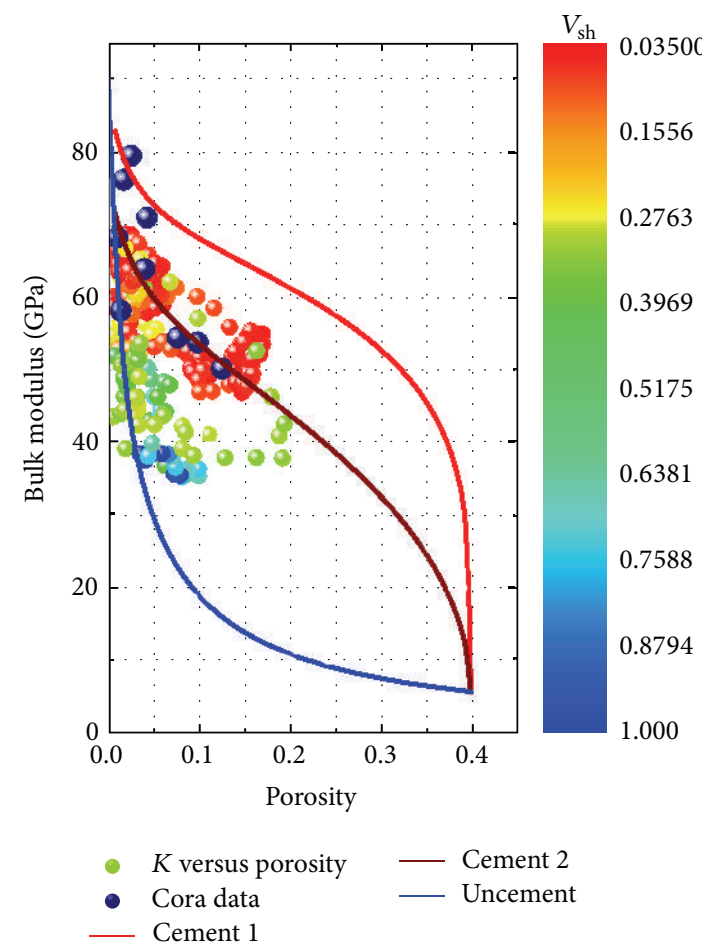

(b)

Figure 9: (a) P-wave velocity versus porosity; and (b) modulus versus porosity (core [11], data included) color coded with shale volume $\left(V_{\text {sh }}\right)$ of the Marmaton section in well number A with rock physics models curves superimposed. 

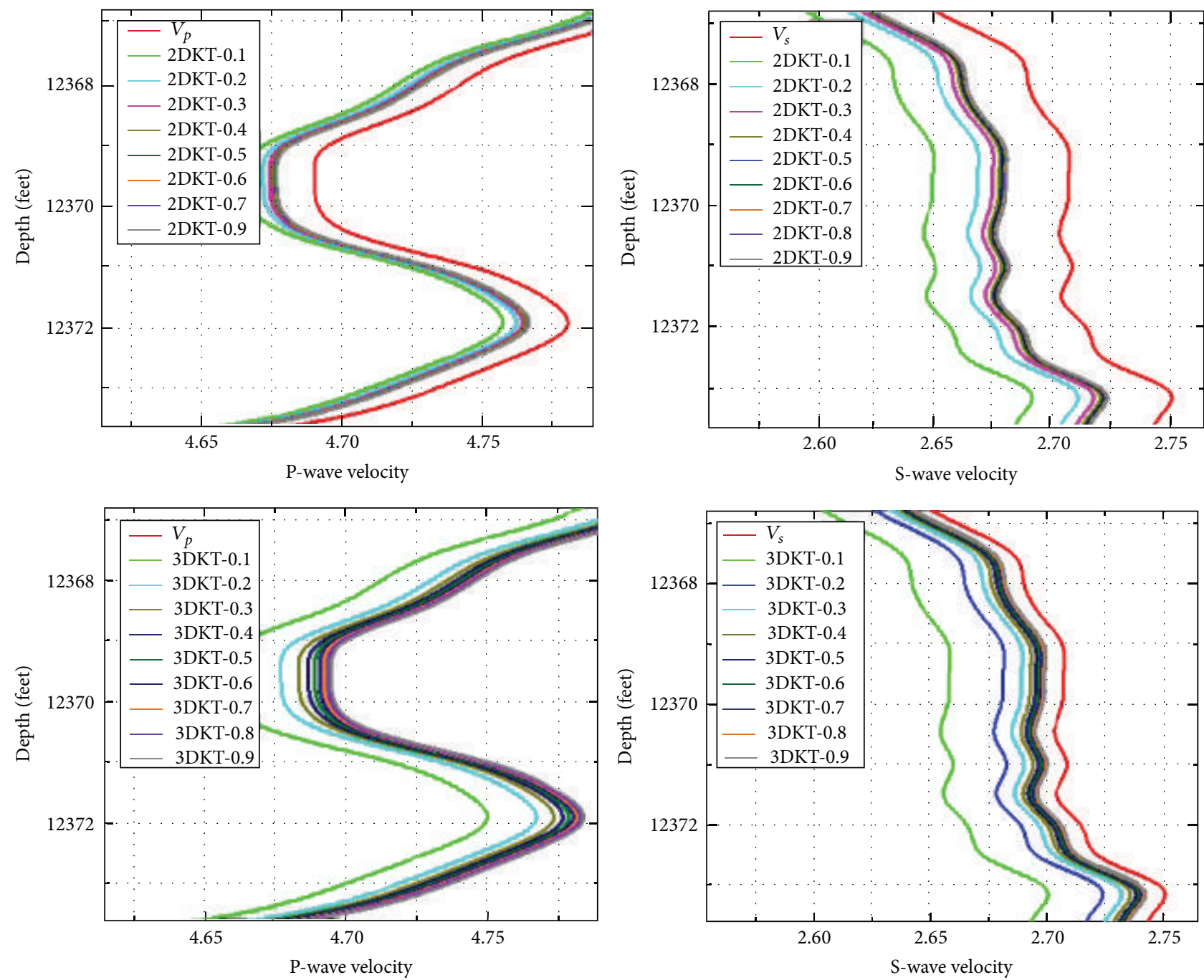

FIGURE 10: P- and S-wave velocities prediction by employing 2DKT and 3DKT models using different aspect ratios (0.1-0.9) of well number A.

interesting that the well-log data with resolution of tensof-centimeter reflects what we observe at the microscale. By establishing a site-specific rock physics transform (uncemented and cemented models) between the total porosity, mineralogy, and elastic properties, we conclude the rock physics diagnostics here. In the next section, we analyze pore shape influence on seismic velocities in order to generate locally calibrated $V_{\mathrm{P}}-V_{\mathrm{S}}$ relationship for Granite Wash.

5.3. Analysis of Pore Shapes Influencing Seismic Velocities. Theoretically, it has been reckoned that the velocities in two states (dry or saturated) are mainly controlled by the effective moduli (bulk and shear), which in turn depend on pore shape geometry, mineralogy, properties of solids, the pore fluid, degree of consolidation, and cementation [9, 26, 27]. Thus, elastic moduli (or velocities) are basically the function of all these factors combined. Especially, in low porosity and permeability rocks, elastic moduli of the rock mineral matrix with spherical pores (high aspect ratio) often dominate those of the bulk rock $[9,26,27]$. Therefore, it is theoretically reasonable to employ the elastic moduli in rocks to estimate seismic velocities. Here, two effective medium (2DKT and 3DKT) models are investigated to evaluate pore shape geometry using different pore aspect ratios (value ranging from 0.1 to 0.9 ) to predict $\mathrm{P}$ - and S-wave velocities from the well data. We know that the pores with high aspect ratio (spherical) tend to be stiffer than those with low aspect ratio (oblate or penny shape pores). That is to say, P- and Swave velocities in the reservoir with spherical pores tend to be higher than one with oblate pores or penny shape. The fact can be easily understood because stiffer pores contribute to the stiffness of the whole rock while oblate pores contribute to the compliance of the whole rock. Here, actual well number $\mathrm{A}$ is taken as an example containing dipole sonic logs to estimate P- and S-wave velocity. From Figure 10, we can see clearly that the increase in $\mathrm{P}$ - and S-wave velocities is sharper when the pore aspect ratio increases from 0.1 to 0.6 for both $2 \mathrm{DKT}$ and $3 \mathrm{DKT}$ models. However, the increasing trend is nominal when the pore aspect ratio exceeds beyond 0.6 in 

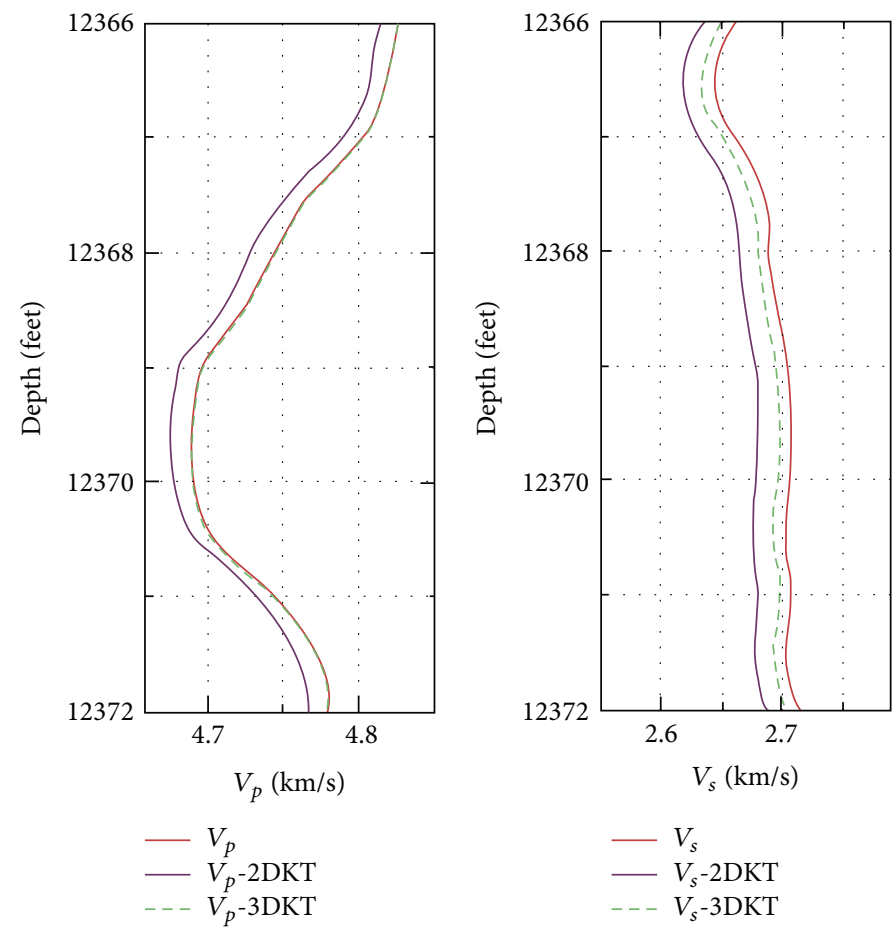

FIGURE 11: A comparison between the predicted and measured P- and S-wave velocities by employing 2DKT and 3DKT models using critical aspect ratio (0.6) of well number A.

both models. Significantly, velocities predicted by the $3 \mathrm{DKT}$ model agree well with those measured compared to the $2 \mathrm{DKT}$ model (Figure 11).

It is due to the fact that the model adjusts pore aspect ratio or the proportion of various $3 \mathrm{D}$ pores and effectively models the geometries of various pore shapes, which is the dominant factor influencing the velocities of the elasticwave propagating in the clastic reservoirs [28]. Due to the substantial amount of clay (15\%), contents that may contain microcracks, the dry rock moduli estimation by the KusterToksoz (2DKT) model (assuming ellipsoidal) could not be appropriate. The addition of small volumes of cracks to the rock matrix significantly weakens the rock. The predicted Pand S-wave velocities from 3DKT are more consistent with the measured ones although with some deviation. Thus, we consider aspect ratio 0.6 as the critical value of the pore aspect ratio, which is the turning point of the increase trend of predicted velocities for Marmaton Wash.

Thus, variations in the elastic moduli are more influenced by pore shape geometry than porosity lower than $10 \%$ and have a relatively small impact on $V_{\mathrm{P}} / V_{\mathrm{S}}$ ratios. The integrated application of the 2DKT and 3DKT models helped us properly determine the pore shape geometry of Granite Wash reservoir to estimate site specific $V_{\mathrm{P}}-V_{\mathrm{S}}$ relationship.

5.4. $V_{P}-V_{S}$ Relationship of Granite Wash. The $V_{\mathrm{P}}-V_{\mathrm{S}}$ relation is normally used for $V_{\mathrm{S}}$ prediction where only $\mathrm{P}$-wave data is available and is also very important for AVO analysis and pore fluids prediction. For S-wave velocity estimation, regardless of the approach taken, it is important to understand the underlying lithology. The rock composition provides first order control on dry frame $V_{\mathrm{P}} / V_{\mathrm{S}}$ ratio, especially for consolidated rocks [29]. We take advantage of rock physics (effective medium) modeling and derive the $V_{\mathrm{P}}-V_{\mathrm{S}}$ relationship and compare it with the widely used empirical relationship " $V_{\mathrm{P}}=1.16 * V_{\mathrm{S}}+1.36$ " presented by Castagna et al. [8] for clastic rocks. We employ Berryman's [7] (3DKT) model considering rock composition, porosity, and pore shape. After calibration of the predicted velocities with core data, the $V_{\mathrm{P}}-V_{\mathrm{S}}$ relationship is generated through regression analysis of least-square linear fit $\left(R^{2}=0.90\right)$ as a function of $V_{\mathrm{P}}(\mathrm{Km} / \mathrm{s})$ (Figure 12).

The derived $V_{\mathrm{P}}-V_{\mathrm{S}}$ relation by $3 \mathrm{DKT}$ for Granite Wash provides closer approximation from $2 \mathrm{DKT}$ and global empirical relation by Castagna et al. [8]. Figure 13 shows that the $\mathrm{S}$-wave velocity derived from Castagna's mudrock is over predicted with known $V_{\mathrm{P}}$ when comparatively analyzed to 2DKT and 3DKT models predictions. However, there are apparent deviations between the measured and predicted data by the locally calibrated empirical relation and the effective medium models. We actually do not advocate the use of global empirical relations for S-wave velocity prediction for the Granite Wash but emphasize on site specific built relation based on the data of the corresponding study area using effective medium models. Next, we employed the best model (3DKT model) to discuss the fluid substitution effects on $\mathrm{P}$ - and S-wave velocities Marmaton Wash.

5.5. Fluid Substitution in Granite Wash. For practical fluid substitution results in tight sands, using Gassmann's [21] 


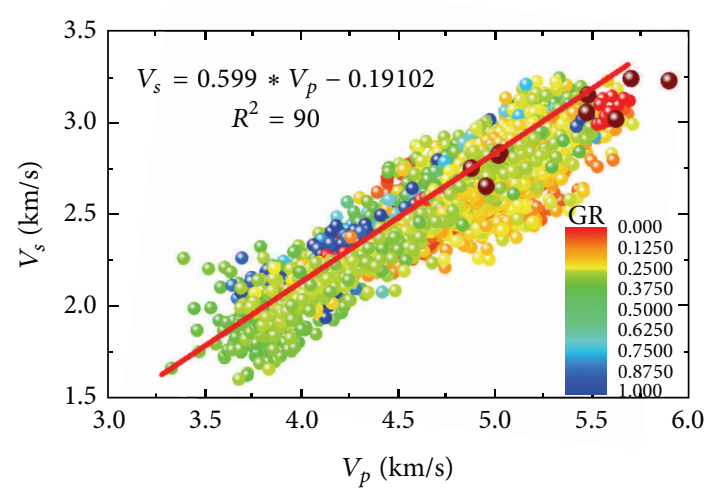

FIGURE 12: Compressional and shear wave velocities of Granite Wash formation from sonic logs data color coded with gamma ray (GR) from two wells numbers A and B and calibrated with core [11] measurements (Maroon data).

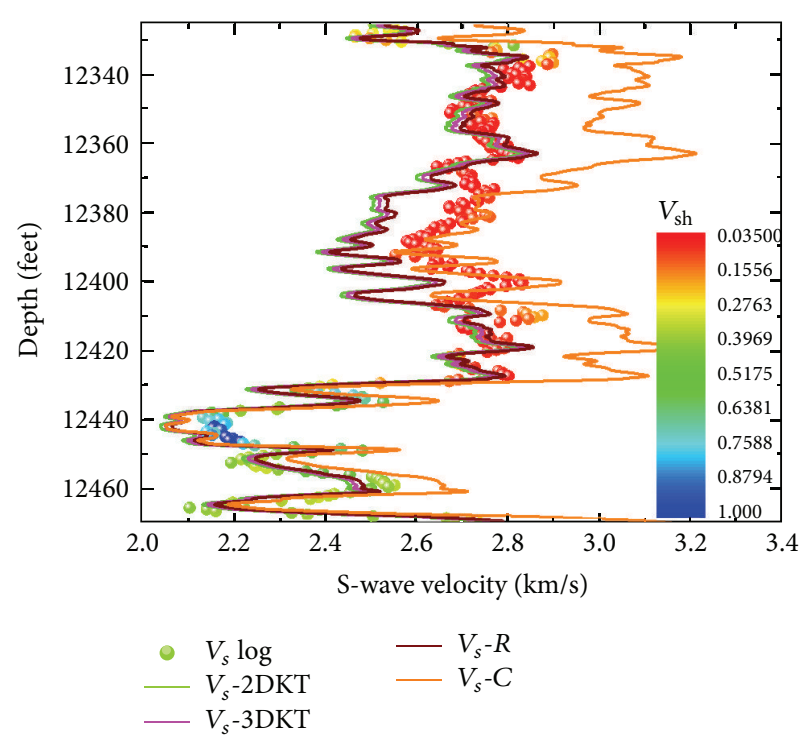

FIGURE 13: Comparison of S-wave velocity predictions (color coded with $V_{\text {sh }}$ ) of well number A with effective medium (2DKT and 3DKT) models, locally generated relation $\left(V_{s}-R\right)$, and Castagna global empirical relationship $\left(V_{s}-C\right)$.

equations necessitates an appropriate technique which realistically stiffens low porosity rock by fluctuating the mineral, pore fluid, or dry rock moduli. Application of Gassmann's equation is dependent upon reasonable estimation of the bulk modulus of the dry rock frame $\left(K_{d}\right)$. Dry frame rock bulk $\left(K_{d}\right)$ modulus can be derived either from (1) laboratory measurement on core data, (2) application of empirical relationships or effective medium theory [30-33], or (3) direct calculation from log data by rewriting Gassmann's equation (4) for frame rock bulk $\left(K_{d}\right)$ [34], which often generates negative (a physical impossibility) or unrealistically large values in low porosity reservoirs [35]. However, of the various alternatives, we take essentially a pragmatic approach to condition the dry frame rock model used in fluid substitution.
For reliable fluid substitution model in clastic reservoir, we conditioned the calculation of dry frame $\left(K_{d}\right)$ rock data implicit in Gassmann's model and apply Biot [36] relation used by Wang et al., [37] as follows:

$$
K_{d}=K_{m}(1-\beta),
$$

where $\beta$ is sometimes called the Biot coefficient and it is often calculated as a function of porosity, and the form used in the paper is derived by Krief et al. [38]

$$
\begin{gathered}
(1-\beta)=[1-\phi]^{m(\phi)}, \\
m(\phi)=\frac{3}{(1-\phi)}
\end{gathered}
$$

where $\phi$ is the formation porosity.

Consequently, the saturated bulk modulus of the rock $\left(K_{\text {sat }}\right)$ for the in situ conditions is first calculated using (1). Equation (7) is combined with Gassmann's equations (4) to generate a pseudo dry frame rock bulk $\left(K_{d}\right)$ modulus suitable for fluid substitution. The input parameters for fluid substitutions are generally roughly estimated and thus result in substantial errors. Therefore, densities, bulk moduli, velocities, and viscosities of various pore fluids (brine and gas) are used both from core measurements and estimation using Batzle and Wang [39] relationships. The homogeneous fluid $\left(K_{\mathrm{fl}}\right)$, uniformly distributed throughout the pore space, has been computed by harmonic average (Reuss) using data from the well logs assuming two fluids (water and gas) phases in the reservoir. The fluids $\left(K_{\mathrm{fl}}, \rho_{\mathrm{fl}}\right)$ properties occupying the pore space and the bulk modulus of the mineral matrix $\left(K_{\text {matrix }}\right)$ are determined by formulations given by Smith et al. [35]. To calculate the bulk modulus of the mineral matrix $\left(K_{\text {matrix }}\right)$, the information on the composition (mineral abundance) of the rock is used from core study data [11]. Mineral matrix $\left(K_{\text {matrix }}\right)$ is then calculated via application of Voigt-ReussHill (VRH) averaging the mineral constituents. The elastic constants and densities of pore fluid properties obtained from core measurements are given in Table 2. Figure 14, an example of composite log example from Granite Wash (Marmaton) section, demonstrates the significant fluid substitution differences between the wet and the gas effect on the seismic Pwave $\left(V_{\mathrm{P}}\right)$ velocity $\log$ for well number $\mathrm{A}$. The observed fluid effects reach a maximum in the cleanest sand with the highest (13\%) porosity and low density response. Fluid substitution effects correspond more closely with expectations based on raw logs, increasing our confidence in the results of AVO modeling and seismic inversion carried out in phase II.

5.6. Cross-Plotting Attribute Analysis. Cross-plotting of elastic rock properties from well logs enables the simultaneous and meaningful evaluation of two attributes that helps in making straightforward interpretation of hydrocarbon saturated sands in a particular reservoir. For comparison, we cross-plotted both conventional (P- and S-impedances) and unconventional (lambda, mu and rho) attributes in the derived elastic parameter cross-plot space to isolate potential anomalous zones from a background relationship of well 


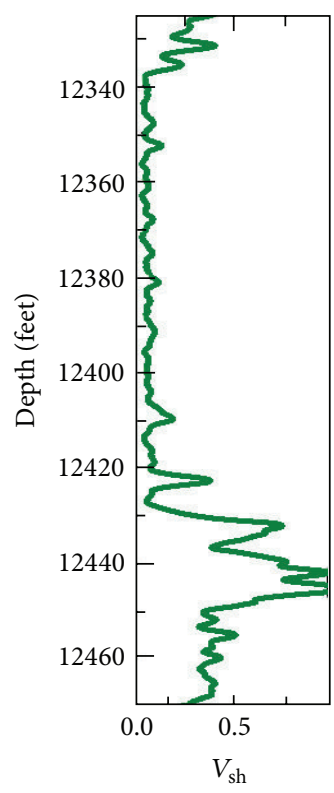

(a)

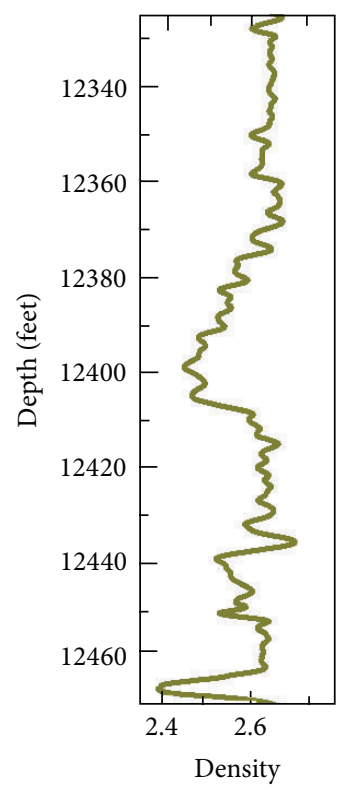

(d)

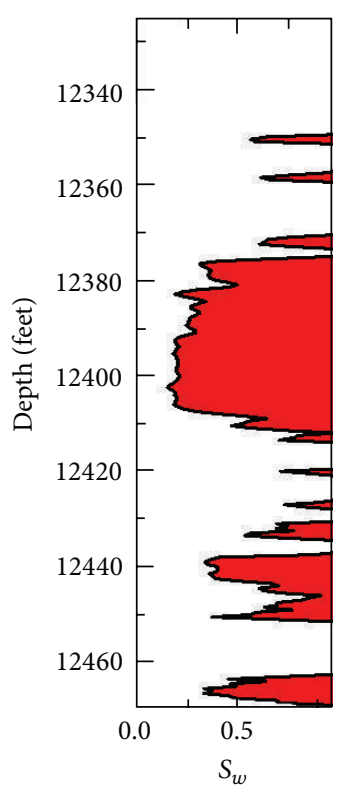

(b)

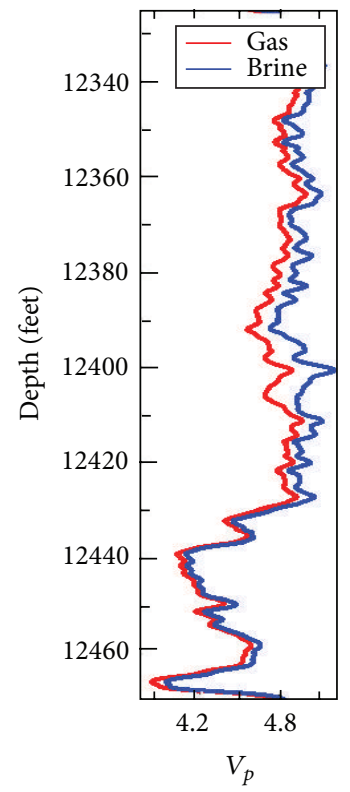

(e)

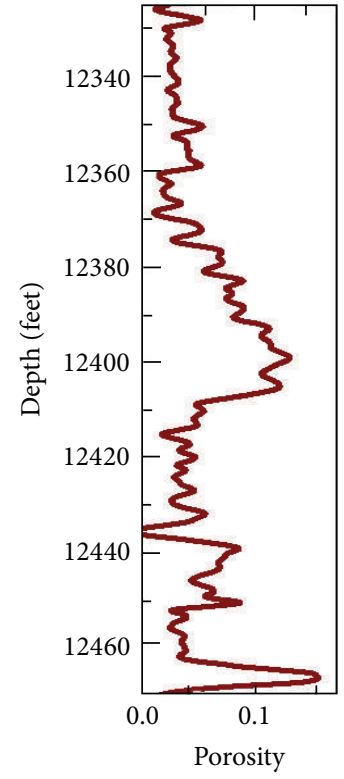

(c)

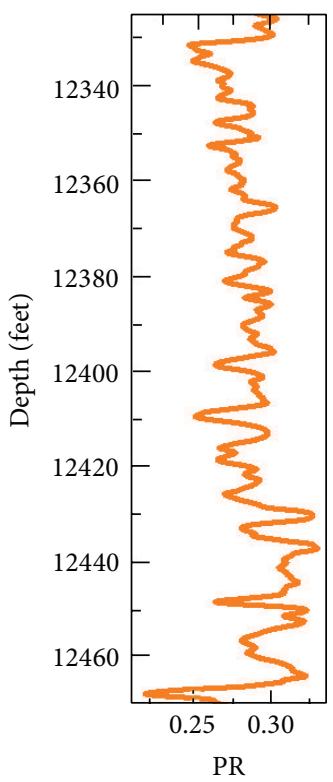

(f)

Figure 14: A composite log example from Granite Wash (Marmaton) section. Plots from left to right show logs of (a) $V_{\text {sh }}$, (b) Water saturation $\left(S_{w}\right)$, (c) porosity, (d) density, (e) compressional velocity $\left(V_{\mathrm{P}}\right)$, and (f) Poisson ratio (PR). Fluid substitution is carried out for brine (blue) and gas (red) scenarios using dry rock data derived from logs.

number A (Figure 15). Figure 15(a) shows where a conventional impedance IP versus IS analysis has limitations in clearly discriminating between all the various lithologies and gas sand zone. The P- and S-impedances log curves (which share both rigidity and density) tend to track each other with depth and never crossover; only S-impedance contrast in the Marmaton sand $\left(12400^{\prime}\right)$ is clearly less distinguishable than the comparable P-impedance contrast. By contrast, the $\lambda \rho$ and $\mu \rho$ attributes have similar value ranges, that do cross over with $\lambda \rho<\mu \rho$ showing a clear, wide separation for a hydrocarbon zone, while tracking together to clearly indicate the thin, tight shale breaks (Figure 15(b)). In Figure 15(c), only the gas zone is discernable from background cut-off on the $V_{\mathrm{P}} / V_{\mathrm{S}}$ curve which varies between 1.6 and 2.0. Figures 15(d) and 15(e) demonstrate the significant advantage of the $\lambda \rho$, $\mu \rho$ cross-plot in isolating both lithologic properties (such as sand, shale, and clastic facies) as well as the gas zone compared to IP and IS cross-plot. P- and S-impedance data points 


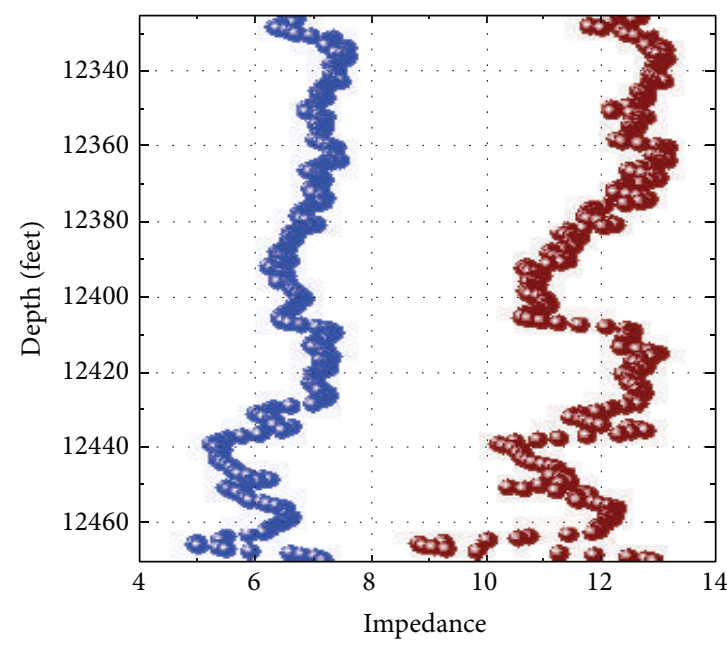

- IP

- IS

(a)

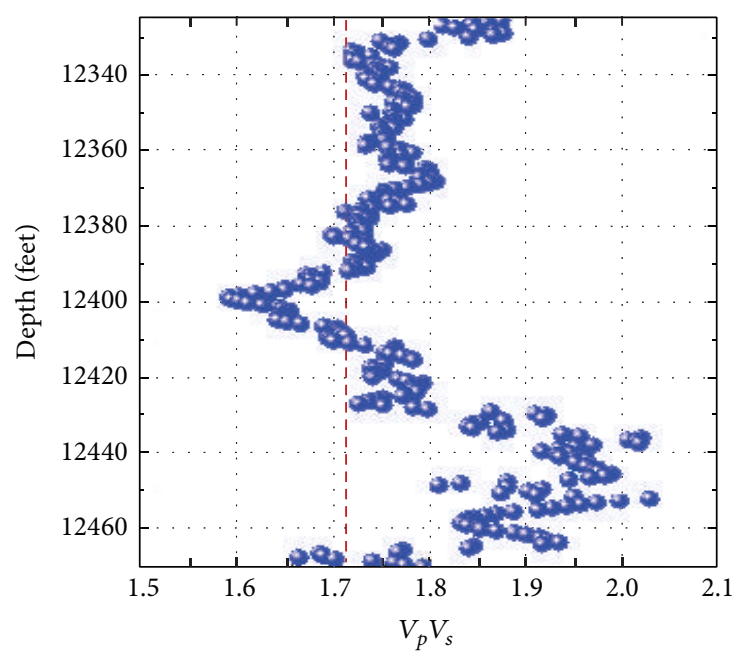

(c)

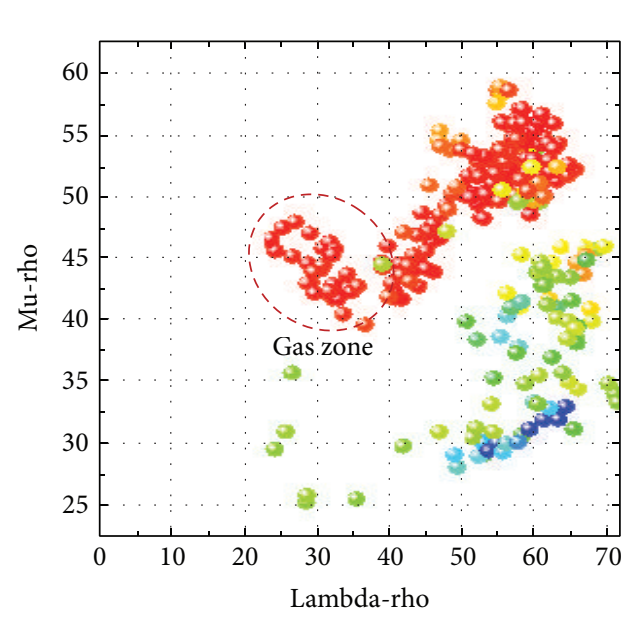

(e)

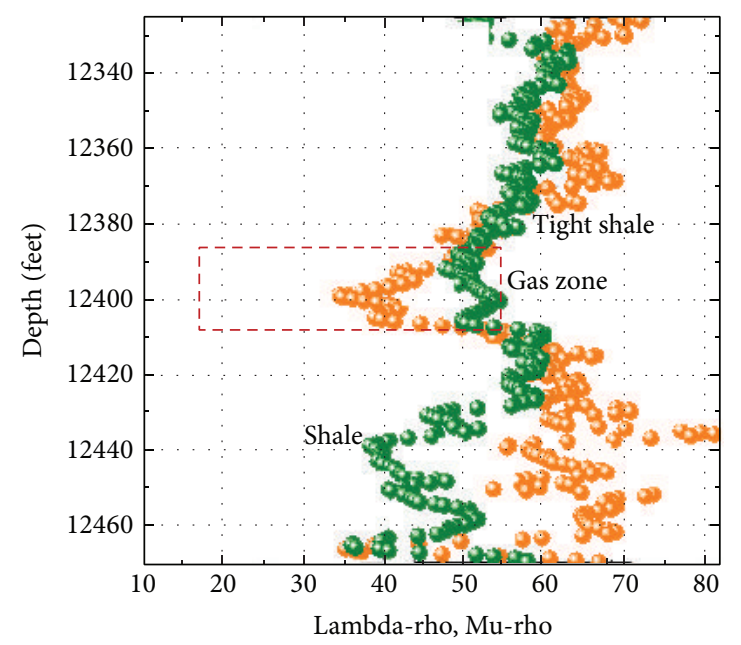

- Lambda-rho

- Mu-rho

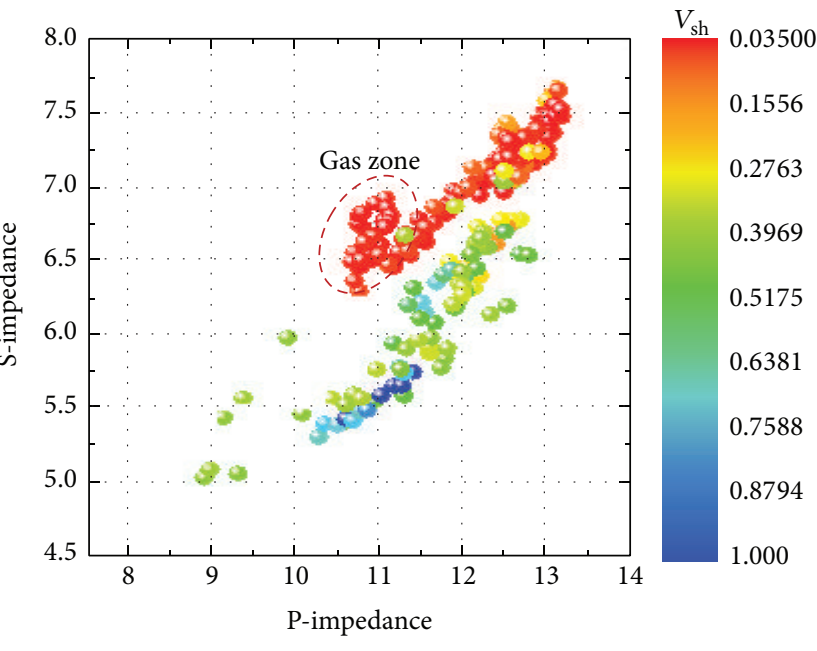

(d)

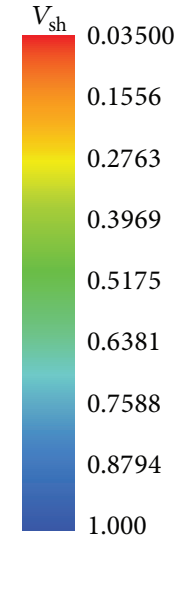

0.1556

.2763

0.3969

0.5175

0.6381

7588

000

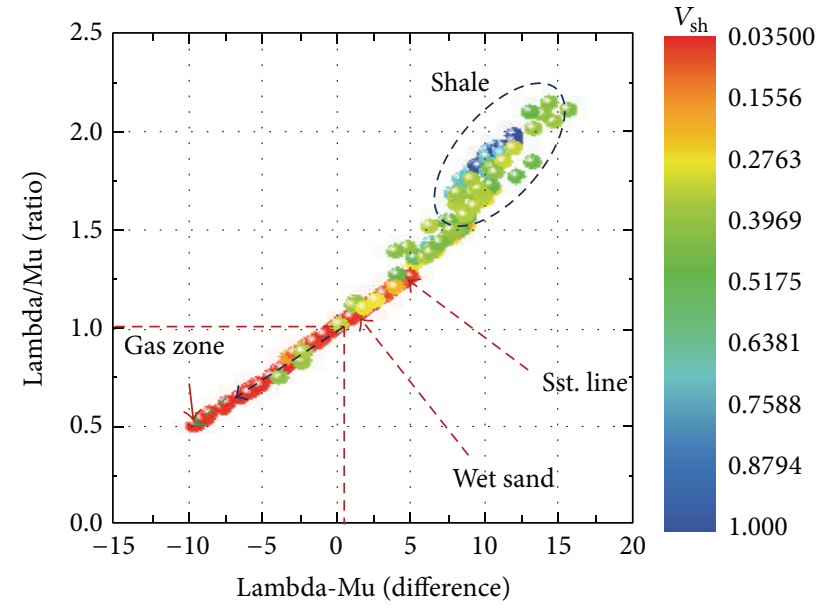

(f)

FIGURE 15: Well log curves and cross-plots from Granite Wash (Marmaton sections 12325-12470) of well number A; (a) P- and S-impedances $\log$ curves; (b) Lambda-rho and Mu-rho log versus depth; (c) $V_{p} V_{s}$ ratio versus depth; (d) P-impedance versus S-impedance cross-plot color coded by shale volume $\left(V_{\mathrm{sh}}\right)$; (e) Lambda-rho versus Mu-rho cross-plot color coded by shale volume $\left(V_{\mathrm{sh}}\right)$; and (f) Lambda-Mu (difference) versus Lambda-rho/Mu-rho (ratio) cross-plot color coded by shale volume $\left(V_{\text {sh }}\right)$. 
show a close linear relationship with shale having lowest values, while in comparison the lowest $\lambda \rho$ (incompressibility $\times$ density) value has the best gas sand values along with $\mu \rho$ (rigidity $\times$ density) values higher than shales. The other more competent pure lithologies (silts, cemented sands) could be observed in the opposite upper right quadrant relative to the shales.

Following the cross-plots analysis for the same log data set, Figure 15(f) shows an interesting interpretation template for the $\lambda / \mu$ ratio versus the $\lambda-\mu$ (difference) cross-plot. The anomalous (gas) zone is marked in a lower left red box beyond the $(0.6,-5)$ point separating it from the wet sands which tend to align in the upper right zone. The variation of the slope beyond the origin $(1,0)$ with increasing gas saturation (blue to green dotted lines) reveals an unexpected effect of the gas on the rigidity of the sand. This is due to the effective porosity and lower density gas effect on rigidity leading to a slight steeping of the "sandstone line" slope. Thus, in this case, unconventional attributes plots provide a clear separation of the anomalous hydrocarbon zones and the lithologic properties of the sand and shale facies which have been color coded with shale volume.

\section{Conclusion}

With the above discussion and limitations, the following conclusions can be derived. Rock physics diagnostic and thin sections analysis indicate the variations in elastic properties of Granite Wash which can be explained by diagenetic phase of quartz (or silica) cementation. Cemented Washes have relatively high elastic moduli and can be modeled primarily by contact-cement model of scheme 2 . Velocity prediction from effective medium models shows that pore shape geometry significantly influences the $\mathrm{P}$ - and S-wave velocities in our reservoirs as observed in the velocity data evaluated. Core and petrographic observations also confirm cementations with complex pore geometry containing variable concentrations of high and low pores aspect ratio. Hence, Berryman's (3DKT) model is proven to be the best one to discuss the influence of pore shape on seismic velocities and used for the generation of locally calibrated empirical $\left(V_{\mathrm{P}}-V_{\mathrm{S}}\right)$ relationship that best describes our data set. Finally, we applied fluid substitution on log data for calculating reservoir elastic properties with different pore fluid (brine and gas) for an improved petrophysical discrimination of rock properties using unconventional Lamé parameters $\lambda$ (pure incompressibility) and $\mu$ (rigidity) attributes over conventional $V_{\mathrm{P}}, V_{\mathrm{S}}$ attributes analysis. The research outcomes are intended to be rigorously used as a foundation for ongoing reservoir characterization study in phase II.

\section{Disclosure}

This paper is developed from an oral and poster presentation at American Association of Petroleum Geologists (AAPG) Annual Convention \& Exhibition, David L. Lawrence Convention Center, Pittsburgh, PA, USA, May 19-22, 2013.

\section{Conflict of Interests}

The authors declare that there is no conflict of interests regarding the publication of this paper.

\section{Acknowledgments}

The authors thank The University of Tulsa and Newfield Exploration Company for support of this research. The first author would like to thank Jeff Kane (Corporate Petrophysicist) for his scholastic discussions. They also thank the anonymous reviewers for the constructive comments on improving our paper.

\section{References}

[1] S. Ingram, I. Paterniti, B. Rothkopf, and C. Stevenson, "Granite wash field study-buffalo wallow field, Texas panhandle," in Proceedings of the SPE Eastern Regional Meeting, SPE104546, Canton, Ohio, USA, October 2006.

[2] M. I. Odigi, "Diagenesis and reservoir quality of Cretaceous sandstone of Nkporo Shale (Campanian) Southeastern Benue trough Nigeria," Journal of Geology and Mining Research, vol. 3, pp. 265-280, 2011.

[3] F. Ruiz and A. Cheng, "A rock physics model for tight gas sand," The Leading Edge, vol. 29, no. 12, pp. 1484-1489, 2010.

[4] R. D. Mindlin, "Compliance of elastic bodies in contact," Journal of Applied Mechanics, vol. 16, pp. 259-268, 1949.

[5] Z. Hashin and S. Shtrikman, "A variational approach to the theory of the elastic behaviour of multiphase materials," Journal of the Mechanics and Physics of Solids, vol. 11, pp. 127-140, 1963.

[6] J. Dvorkin and A. Nur, "Elasticity of high-porosity sandstones: theory for two North Sea data sets," Geophysics, vol. 61, no. 5, pp. 1363-1370, 1996.

[7] J. G. Berryman, "Long-wavelength propagation in composite elastic media II. Ellipsoidal Inclusions," The Journal of the Acoustical Society of America, vol. 68, no. 6, pp. 1820-1831, 1980.

[8] J. P. Castagna, M. L. Batzle, and R. L. Eastwood, "Relationships between compressional-wave and shear-wave velocities in clastic silicate rocks," Geophysics, vol. 50, no. 4, pp. 571-581, 1985.

[9] G. T. Kuster and M. N. Toksoz, "Velocity and attenuation of seismic waves in two-phase media," Geophysics, vol. 39, no. 5, pp. 587-618, 1974.

[10] G. E. Moore, "Pennsylvanian paleogeography of the southern Mid-Continent," in Pennsylvanian Sandstones of the MidContinent, N. J. Hyne, Ed., pp. 2-12, Tulsa Geological Society (TGS), Tulsa, Okla, USA, 1979.

[11] Core Lab, "Granite Wash: geological, Petrophysical and completions study for improved formation evaluation and optimal well completion," Proprietary industry study, 2005.

[12] K. S. Johnson and B. J. Cardott, "Geologic framework and hydrocarbon source rocks of Oklahoma," in Proceedings of the Source Rocks in the Southern Midcontinent, K. S. JohnsonB and J. Cardott, Eds., pp. 21-37, OGS Circular, 1992.

[13] N. R. Gelphman, "West sentinel oil field, Washita County, Oklahoma: sedimentology of the "Granite Wash" and structural geology," Oklahoma City Geological Society Shale Shaker, vol. 10, pp. 234-247, 1960. 
[14] L. R. Brown Jr., "Deltaic sandstone facies of the midcontinent," in Pennsylvanian Sandstones of the Midcontinent, vol. 1, pp. 3563, Tulsa Geological Society (TGS), Special Publication, Tulsa, Okla, USA, 1979.

[15] S. P. Dutton, "Pennsylvanian fan-delta and carbonate deposition, Mobeetie Field, Texas Panhandle.," The American Association of Petroleum Geologists Bulletin, vol. 66, no. 4, pp. 389-407, 1982.

[16] J. W. Neasham, "Applications of scanning electron microscopy to the characteristics of hydrocarbon-bearing rocks," Scanning Electron Microscopy, vol. 1, pp. 101-108, 1977.

[17] D. Han and M. L. Batzle, "Gassmann's equation and fluid-saturation effects on seismic velocities," Geophysics, vol. 69, no. 2, pp. 398-405, 2004.

[18] G. Mavko, T. Mukerji, and J. Dvorkin, The Rock Physics Handbook, Cambridge University Press, New York, NY, USA, 2009.

[19] J. Dvorkin, G. Mavko, and A. Nur, "The effect of cementation on the elastic properties of granular material," Mechanics of Materials, vol. 12, no. 3-4, pp. 207-217, 1991.

[20] J. Dvorkin, A. Nur, and H. Yin, "Effective properties of cemented granular materials," Mechanics of Materials, vol. 18, no. 4, pp. 351-366, 1994.

[21] F. Gassmann, Über die elastizitätporösermedien: Veirteljahrsschrift der NaturforschendenGesellschaft in Zürich, vol. 96, 1951, English translation, http://sepwww.stanford.edu/sep/berryman/PS/gassmann.pdf.

[22] P. Avseth, T. Mukerji, and G. Mavko, Quantitative Seismic Interpretation: Applying Rock Physics Tools to Reduce Interpretation Risk, Cambridge University Press, Cambridge, Mass, USA, 2005.

[23] S. L. Herron, M. M. Herron, and R. A. Plumb, "Identification of clay-supported and framework-supported domains from geochemical and geophysical well log data," in Proceedings of the SPE Annual Technical Conference and Exhibition, vol. 24726, pp. 667-680, October 1992.

[24] D. Marion, Acoustical, mechanical and transport properties of sediments and granular materials [Ph.D. thesis], Stanford University, 1990.

[25] D. Fairbairn, "Synthetic quartzite," American Mineralogist, vol. 35, pp. 735-748, 1950.

[26] D. H. Han, A. Nur, and D. Morgan, "Effects of porosity and clay content on wave velocities in sandstones," Geophysics, vol. 51, no. 11, pp. 2093-2107, 1986.

[27] F. Ruiz and J. Dvorkin, "Predicting elasticity in nonclastic rocks with a differential effective medium model," Geophysics, vol. 75, no. 1, pp. E41-E53, 2010.

[28] H. Wang, S. Z. Sun, H. Yang, H. Gao, Y. Xiao, and H. Hu, “The influence of pore structure on P- \& S-wave velocities in complex carbonate reservoirs with secondary storage space," Petroleum Science, vol. 8, no. 4, pp. 394-405, 2011.

[29] T. M. Smith, "Practical seismic petrophysics: the effective use of log data for seismic analysis," The Leading Edge, vol. 30, no. 10, pp. 1128-1141, 2011.

[30] B. Budiansky and R. J. O'connell, "Elastic moduli of a cracked solid," International Journal of Solids and Structures, vol. 12, no. 2, pp. 81-97, 1976.

[31] W. Murphy and A. Reischer, "Modulus decomposition of compressional and shear velocities in sand bodies," Geophysics, vol. 58, no. 2, pp. 227-239, 1993.

[32] J. W. Spencer Jr., M. E. Cates, and D. D. Thompson, "Frame moduli of unconsolidated sands and sandstones," Geophysics, vol. 59, no. 9, pp. 1352-1361, 1994.
[33] Z. Wang, "Fundamentals of seismic rock physics," Geophysics, vol. 66, no. 2, pp. 398-412, 2001.

[34] X. Zhu and G. A. McMechan, "Direct estimation of the bulk modulus of the frame in fluid saturated elastic medium by Biot theory," in Proceedings of the 60th Annual International Meeting, Society of Exploration Geophysicist (SEG'90), pp. 787-790, 1990.

[35] T. M. Smith, C. H. Sondergeld, and C. S. Rai, "Gassmann fluid substitutions: a tutorial," Geophysics, vol. 68, no. 2, pp. 430-440, 2003.

[36] M. A. Biot, "Theory of propagation of elastic waves in a fluidsaturated porous solid. II. Higher frequency range," The Journal of the Acoustical Society of America, vol. 28, pp. 179-191, 1956.

[37] H. Wang, S. Z. Sun, Y. Li, and X. Li, "Evaluation and improvement of velocity-prediction models and fluid substitution for argilliferous clastic reservoirs rock," in Proceedings of the International Exposition and Annual Meeting, Society of Exploration Geophysicists (SEG), Houston, Tex, USA, 2009.

[38] M. Krief, J. Garat, J. Stellingwerff, and J. Ventre, "A petrophysical interpretation using the velocities of $\mathrm{P}$ and $\mathrm{S}$ waves (fullwaveform sonic)," The Log Analyst, vol. 31, pp. 355-369, 1990.

[39] M. Batzle and Z. Wang, "Seismic properties of pore fluids," Geophysics, vol. 57, no. 11, pp. 1396-1408, 1992. 

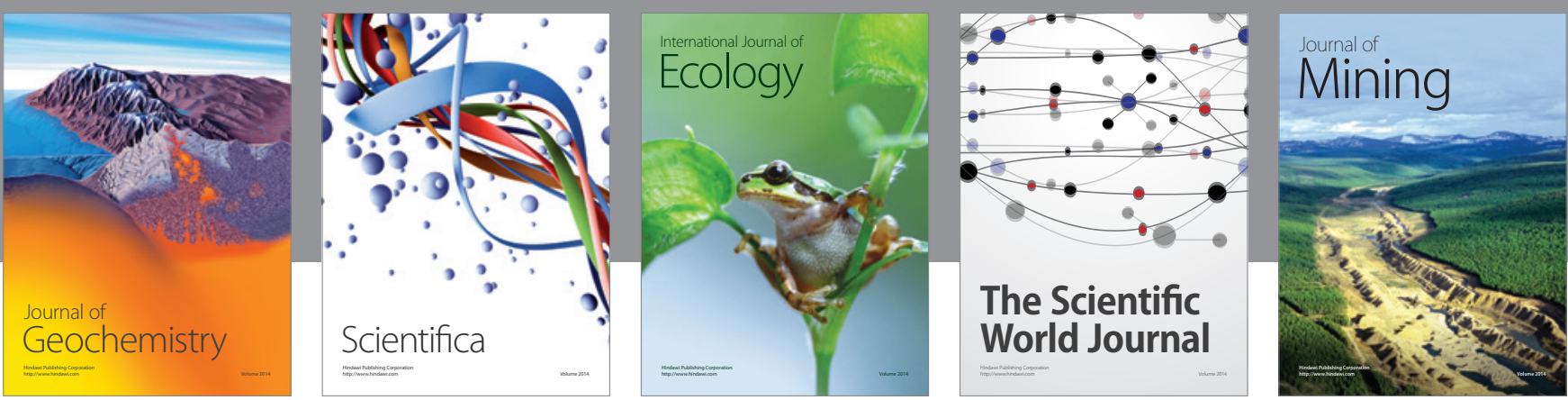

The Scientific World Journal
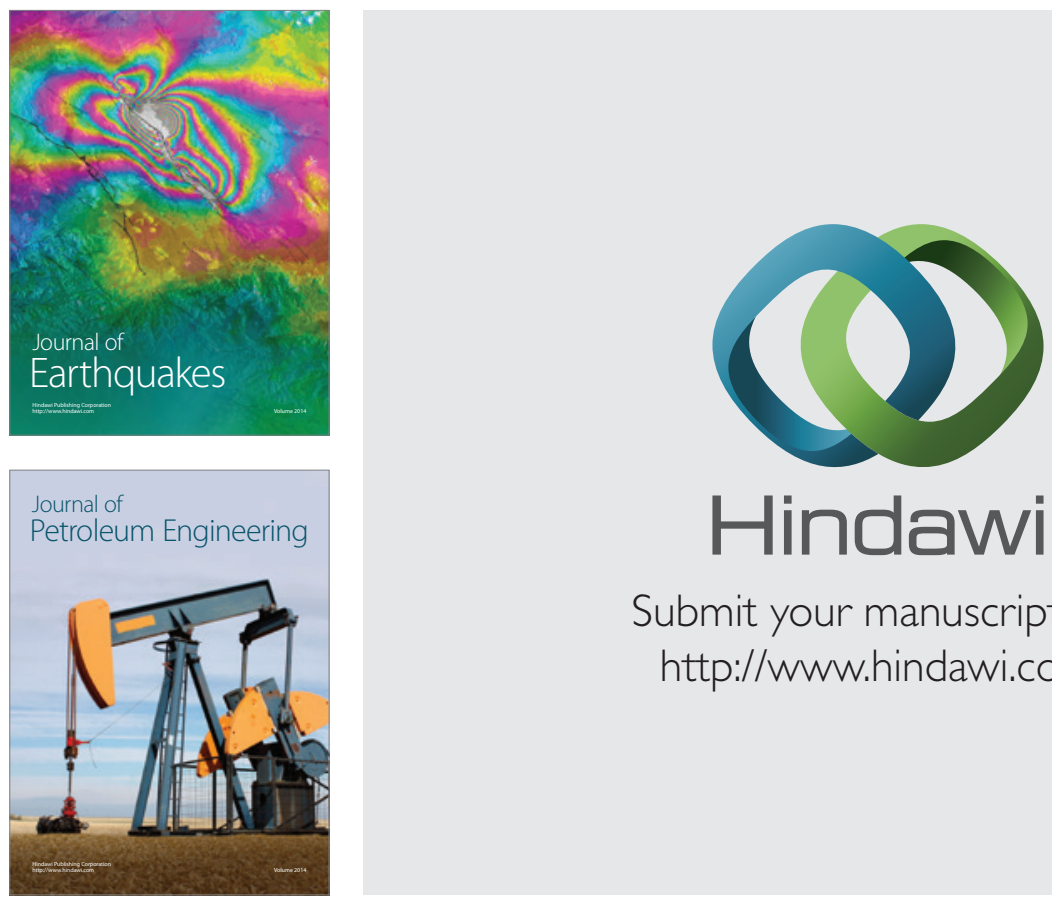

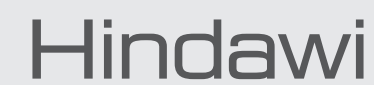

Submit your manuscripts at

http://www.hindawi.com
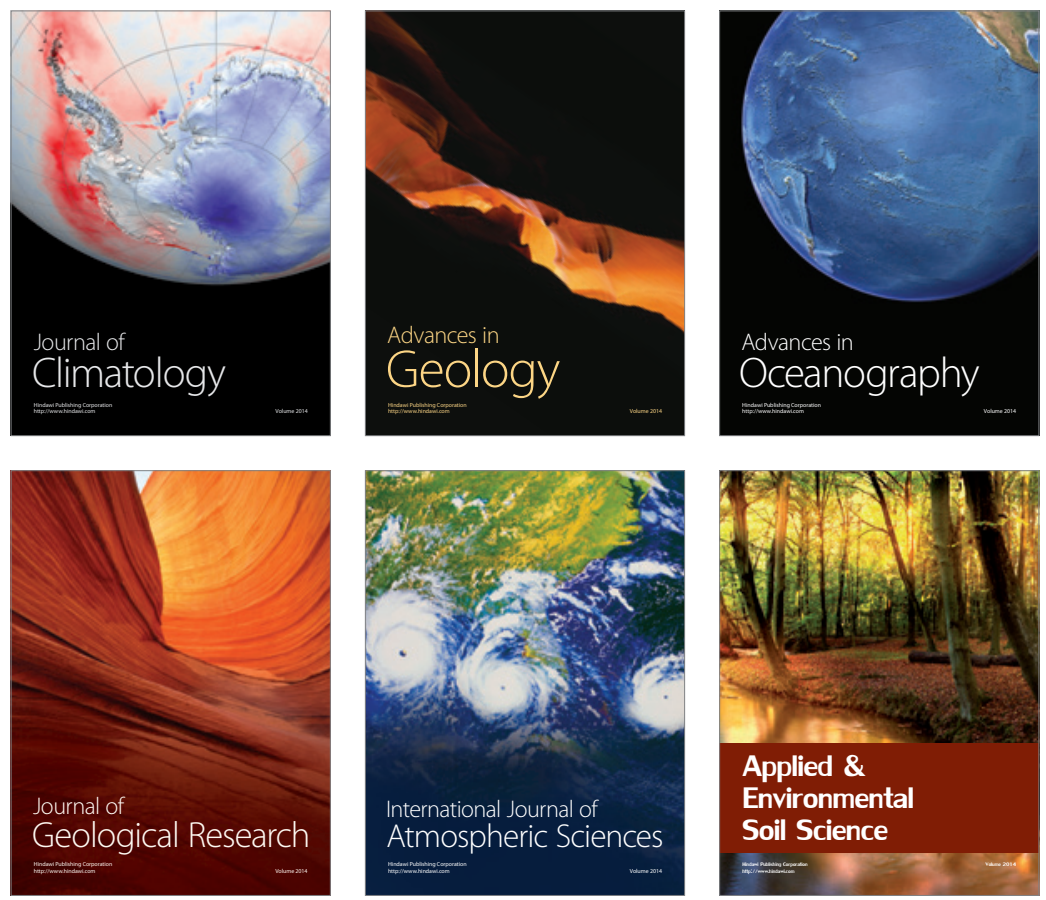
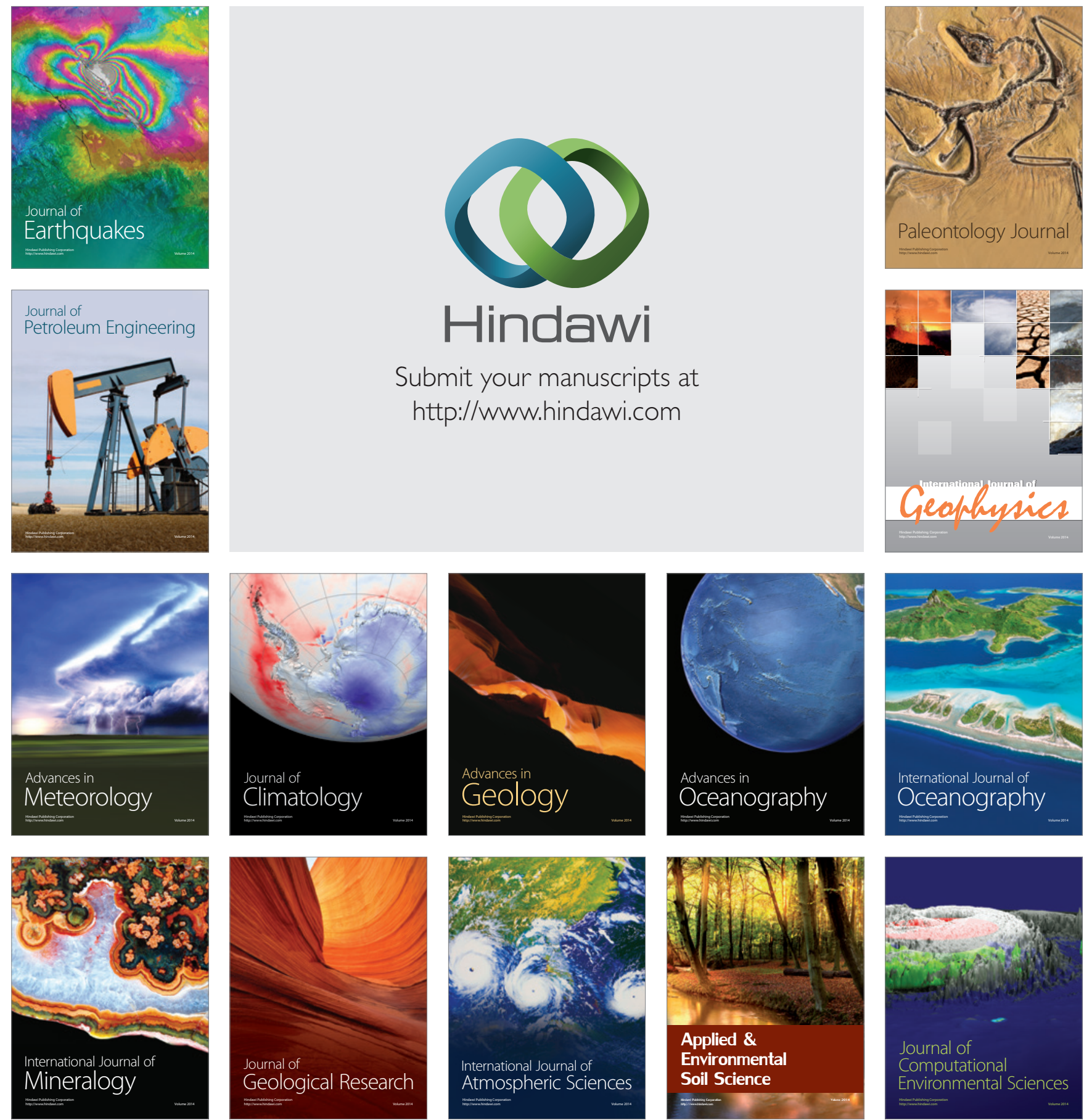